\title{
Comparative toxicity and biodistribution of copper nanoparticles and cupric ions in rats
}

\author{
This article was published in the following Dove Press journal: \\ International Journal of Nanomedicine \\ 16 June 2016 \\ Number of times this article has been viewed
}

\author{
In-Chul Lee' \\ Je-Won Ko' \\ Sung-Hyeuk Park' \\ Je-Oh Lim' \\ In-Sik Shin' \\ Changjong Moon' \\ Sung-Hwan Kim² \\ Jeong-Doo $\mathrm{Heo}^{3}$ \\ Jong-Choon Kim'
}

'College of Veterinary Medicine BK2I Plus Project Team, Chonnam National University, Gwangju, ${ }^{2} J$ eonbuk Department of Inhalation Research, Korea Institute of Toxicology, Jeongeup, ${ }^{3}$ Gyeongnam Department of Environment and Toxicology, Korea Institute of Toxicology, Gyeongnam, Republic of Korea
Correspondence: Jeong-Doo Heo Gyeongnam Department of Environment and Toxicology, Korea Institute of Toxicology, 17 Jegok-gil, Jinju, Gyeongnam 660-844, Republic of Korea Email jdher@kitox.re.kr

Jong-Choon Kim

College of Veterinary Medicine BK2I

Plus Project Team, Chonnam National University, Gwangju 500-757, Republic of Korea

Tel +82 625302827

Email toxkim@jnu.ac.kr
Abstract: Despite widespread use and prospective biomedical applications of copper nanoparticles ( $\mathrm{Cu}$ NPs), their biosafety issues and kinetics remain unclear. Thus, the aim of this study was to compare the detailed in vivo toxicity of $\mathrm{Cu}$ NPs and cupric ions $\left(\mathrm{CuCl}_{2} ; \mathrm{Cu}\right.$ ions $)$ after a single oral dose. We determined the physicochemical characteristics of $\mathrm{Cu} N P s$, including morphology, hydrodynamic size, zeta potential, and dissolution in gastric $(\mathrm{pH} 1.5)$, vehicle ( $\mathrm{pH}$ 6.5), and intestinal ( $\mathrm{pH} 7.8$ ) conditions. We also evaluated the kinetics of Cu following a single equivalent dose $(500 \mathrm{mg} / \mathrm{kg})$ of $\mathrm{Cu}$ NPs and $\mathrm{Cu}$ ions. Cu NPs had highest dissolution $(84.5 \%)$ only in gastric conditions when compared with complete dissolution of $\mathrm{Cu}$ ions under various physiological milieus. Kinetic analysis revealed that highest $\mathrm{Cu}$ levels in blood and tested organs of $\mathrm{Cu}$ NP-treated rats were $15 \%-25 \%$ lower than that of $\mathrm{Cu}$ ions. Similar to the case of $\mathrm{Cu}$ ions, $\mathrm{Cu}$ levels in the tested organs (especially liver, kidney, and spleen) of $\mathrm{Cu}$ NP-treated rats increased significantly when compared with the vehicle control. However, delay in reaching the highest level and biopersistence of $\mathrm{Cu}$ were observed in the blood and tested organs of $\mathrm{Cu}$ NP-treated rats compared with $\mathrm{Cu}$ ions. Extremely high levels of $\mathrm{Cu}$ in feces indicated that unabsorbed $\mathrm{Cu}$ NPs or absorbed $\mathrm{Cu}$ ions were predominantly eliminated through liver/feces. $\mathrm{Cu}$ NPs exerted apparent toxicological effects at higher dose levels compared with $\mathrm{Cu}$ ions and showed sex-dependent differences in mortality, biochemistry, and histopathology. Liver, kidney, and spleen were the major organs affected by $\mathrm{Cu}$ NPs. Collectively, the toxicity and kinetics of $\mathrm{Cu}$ NPs are most likely influenced by the release of $\mathrm{Cu}$ dissociated from $\mathrm{Cu}$ NPs under physiological conditions.

Keywords: copper nanoparticles, cupric ions, comparative toxicity, toxicokinetics

\section{Introduction}

In recent years, scientific research on nanoparticles (NPs) has shown a tremendous and rapid growth owing to their wide applications in various fields, including electronics, cosmetics, food industry, and medicine. ${ }^{1-3}$ The use of fabricated NPs has great potential in a wide range of applications, since their distinct physicochemical characteristics can be utilized in an application-specific manner by modifying their size, surface properties, and shape. ${ }^{4}$ However, their unique physicochemical properties may affect their toxicological behavior in vivo by facilitating cellular uptake and translocation of the particles in the body. ${ }^{5,6}$ Furthermore, the physiological milieu influences the interaction between biological systems and NPs and can determine the fate and biosafety of NPs. ${ }^{7}$ Currently, with the widespread use of NPs, health risks and environmental effects related to NP exposure have become of great concern. ${ }^{8}$ In addition, the applications of NPs have been limited by lack of verification of biosafety. ${ }^{9-11}$ Thus, a detailed evaluation of their potential toxicity in vivo must precede any prospective applications. ${ }^{12}$ 
Copper $(\mathrm{Cu})$ is an essential element required for normal physiological functions in humans and animals, including hemoglobin formation, drug metabolism, carbohydrate metabolism, catecholamine biosynthesis, and antioxidant defense mechanism. ${ }^{13,14}$ However, when the intake of $\mathrm{Cu}$ exceeds the range of biological tolerance, it can cause adverse effects, including hemolysis, gastrointestinal distress, and liver and kidney damage. ${ }^{15,16}$ Recent toxicological investigations of NPs have revealed that they tend to exhibit quite different toxicological effects in vivo compared with larger particles of the same chemical composition. ${ }^{17-19}$ Copper nanoparticles ( $\mathrm{Cu}$ NPs) and their oxidized form, copper oxide $(\mathrm{CuO}) \mathrm{NPs}$, are widely used as additives in livestock and poultry feed, polymers/plastics, and lubricants for metallic coating. ${ }^{20}$ The excellent thermophysical properties of $\mathrm{Cu}$ NPs raise their value for applications in the field of electronics technology, such as semiconductors, electronic chips, and heat transfer nanofluids. ${ }^{20,21}$ In addition, synthesis of $\mathrm{Cu}$ NPs is cost effective, and the synthesized $\mathrm{Cu}$ NPs display antimicrobial activity against a wide range of pathogenic microorganisms. Such advantages of NPs have put them in the spotlight as an alternative antimicrobial agent in many biomedical applications. ${ }^{22-24}$ Despite the great potential of $\mathrm{Cu}$ NPs in biomedical applications, toxicity studies of $\mathrm{Cu}$ NPs and $\mathrm{CuO}$ NPs have been mostly limited to in vitro studies. $\mathrm{Cu}$ NPs exhibit cytotoxic effects on various cell lines. ${ }^{25-31}$ Additionally, $\mathrm{CuO}$ NPs have high cytotoxicity compared with conventional metal oxide NPs and carbon nanotubes. ${ }^{32}$ Although there are increasing numbers of in vitro studies, only few reports investigated the in vivo toxicity of $\mathrm{Cu}$ NPs. ${ }^{17,33-35}$ The acute toxicity study of $\mathrm{Cu}$ NPs and $\mathrm{Cu}$ ions has been previously conducted in mice. ${ }^{17}$ The kinetics were evaluated limitedly on serum, kidney, and urine for 72 hours after exposure. ${ }^{35}$ Despite these, limited information concerning the toxicity and kinetics was available. Furthermore, there was no information on biopersistence and excretion data of $\mathrm{Cu}$ NPs for long periods after exposure. For their practical applications, it is highly desirable to make a detailed and systematic study on the toxicity of $\mathrm{Cu}$ NPs and their kinetics in vivo. In this study, we conducted a detailed toxicity study and analyzed the biodistribution in a variety of other organs, including liver, brain, lung, heart, and spleen for 4 weeks, after single exposure. Combined with toxicity data, kinetics data for long term can provide valuable information about biopersistence/clearance and lead to better understanding of toxicity profiles of $\mathrm{Cu}$ NPs.

Herein, we determined the morphological and physicochemical properties of $\mathrm{Cu}$ NPs. Compared with other routes of exposure, gastrointestinal route has potential for wide exposure of the public to higher dose of NPs due to more frequent ingestion via water, food, cosmetics, and drugs. ${ }^{36,37}$ Thus, we investigated the in vivo toxicity and kinetics of $\mathrm{Cu}$ NPs following oral exposure. To evaluate their in vivo toxicity, we performed a single oral dose toxicity study of $\mathrm{Cu}$ NPs in rats by evaluating mortality, biochemical parameters, and histopathology. In addition, we conducted a comparative toxicity study with their ionic form copper(II) chloride $\left(\mathrm{CuCl}_{2}\right.$, $\mathrm{Cu}$ ions) to investigate whether in vivo toxicity of $\mathrm{Cu}$ NPs is influenced by the release of $\mathrm{Cu}$ dissociated from $\mathrm{Cu}$ NPs in physiological conditions when administered orally. In vivo kinetic study of nanoparticulate form and ionic forms of $\mathrm{Cu}$ was conducted to better understand the correlation between in vivo toxicity and their fate in biological systems, which can provide information regarding the biocompatibility of $\mathrm{Cu}$ NPs for their further application.

\section{Materials and methods Test chemicals and treatment}

Cu NPs (CAS no 7440-50-8; 99.8\% purity) were purchased from Skyspring Nanomaterials (Houston, TX, USA). The average particle size measured by transmission electron microscopy (TEM) and specified by manufacturer was $25 \mathrm{~nm}$. Copper(II) chloride (CAS no 10125-13-0; $\mathrm{CuCl}_{2},>99.9 \%$ purity, molecular weight: $134.45 \mathrm{~g} / \mathrm{mol}$ ) purchased from Sigma-Aldrich Co. (St Louis, MO, USA) used as $\mathrm{Cu}$ ions. Hydroxypropylmethylcellulose (HPMC) (Sigma-Aldrich Co.) was used as a suspending vehicle. All other chemicals were of the highest grade commercially available. $\mathrm{Cu}$ NPs and $\mathrm{Cu}$ ions were dispersed into 1\% HPMC solution (w/v) with Milli-Q water. The suspensions containing $\mathrm{Cu}$ NPs were prepared with ultrasonic dispersion (VCX130; Vibra Cell Sonics \& Materials, Newtown, CT, USA) on ice for 20 minutes $(130 \mathrm{~W}, 20 \mathrm{kHz}$, pulse 59/1) and vibrated for 2 minutes. To ensure that did not aggregate before administration, the time interval from preparation to oral gavage was limited to $<20$ minutes.

\section{Physicochemical characterization of Cu NPs}

Primary particle size and morphology were measured using TEM (JEM-2100F; JEOL, Tokyo, Japan) at an accelerating voltage of $150 \mathrm{kV}$ and scanning electron microscopy (SEM; Zeiss EVO-MA10; Carl Zeiss Meditec AG, Jena, Germany) at an accelerating voltage of $15 \mathrm{kV}$. Samples for TEM analysis were prepared using a drop of solution of suspended NPs on carbon-coated nickel grids. The films on the TEM grids 
were allowed to dry before measurement. Samples for SEM analysis were dispersed onto double-sided adhesive carbon tape in an aluminum SEM stub and then dusted to release loose particles. The purity of NP powder was determined by energy-dispersive X-ray spectroscopy (JEM-2100F TEM equipped with X-Max ${ }^{\mathrm{N}} 150 \mathrm{~mm}^{2}$ silicon drift detector; Oxford Instruments, Abingdon, UK). Hydrodynamic size and zeta potential of NPs were measured using ELS-8000 (Otsuka Electronics, Tokyo, Japan). Briefly, the optimal concentration of $\mathrm{Cu}$ NPs for measurement was determined by serial dilution under following conditions: temperature $25^{\circ} \mathrm{C}$, refractive index 1.33 , scattering angle $172^{\circ}$, and laser wavelength $633 \mathrm{~nm}$. The zeta potential of NPs was measured under acidic conditions (artificial gastric fluid [AGF], pH 1.5) to simulate acidic gastric environment, vehicle conditions ( $\mathrm{pH}$ 6.5), and basic conditions (deionized water, $\mathrm{pH}$ 7.8) to simulate the environment in the small intestine. Specific surface area of $\mathrm{Cu} \mathrm{NP}$ powder was measured by the nitrogen absorption methods based on the multipoint Brunauer-Emmett-Teller method (ASAP2020; Micromeritics, Norcross, GA, USA). The levels of endotoxin in NP suspension were determined using a Pierce LAL Chromogenic Endotoxin Quantitation Kit (Thermo Fisher Scientific, Waltham, MA, USA).

\section{Dissolution of $\mathrm{Cu}$ NPs and $\mathrm{Cu}$ ions in physiological conditions}

The dissolution of $\mathrm{Cu}$ NPs and $\mathrm{Cu}$ ions was determined using above three $\mathrm{pH}$ conditions (AGF, vehicle, and deionized water) after 24 hours incubation. AGF was prepared according to a method described previously. ${ }^{38}$ Briefly, $2.0 \mathrm{~g}$ $\mathrm{NaCl}$ and $3.2 \mathrm{~g}$ pepsin (Sigma-Aldrich Co.) were dissolved in $1 \mathrm{~L}$ of deionized water, and then the $\mathrm{pH}$ was adjusted to 1.5 using $2 \mathrm{~N} \mathrm{HCl}$ (Sigma-Aldrich Co.). A total of $5 \mathrm{mg} / \mathrm{mL}$ of $\mathrm{Cu}$ NPs and $\mathrm{Cu}$ ions were incubated in the above solutions for 24 hours. After incubation, NP-free supernatants were collected by three repeated centrifugation at $15,000 \times g$ for 30 minutes. Supernatant samples were weighed $\sim \mathrm{g}$ in $55 \mathrm{~mL}$ microwave digestion vessel and digested with $10 \mathrm{~mL}$ of concentrated nitric acid and $1 \mathrm{~mL}$ of $30 \% \mathrm{H}_{2} \mathrm{O}_{2}$ overnight. It was heated in a microwave digestion system (ETHOS One; Milestone, Sorisole, Italy). Microwave digestion system condition was $40^{\circ} \mathrm{C}$ for 1 minute, $100^{\circ} \mathrm{C}$ for 20 minutes, $170^{\circ} \mathrm{C}$ for 2 hours to remove the remaining nitric acid and then allowed to cool. After samples were completely digested and colorless, the remaining solutions were diluted with $2 \%$ nitric acid. The degree of ionization was evaluated by determining $\mathrm{Cu}^{63}$, and their interference species $\left(\mathrm{PO}_{2}\right.$, $\mathrm{TiO}, \mathrm{ArNa}$, etc) were excluded by methane gas. $\mathrm{Cu}$ analysis of each sample was carried out using inductively coupled plasma mass spectrometry (ICP-MS; NexION 300X; PerkinElmer Inc., Waltham, MA, USA). Cu standard solutions for ICP-MS calibration were prepared at concentrations of $5 \mathrm{ng} / \mathrm{g}, 10 \mathrm{ng} / \mathrm{g}, 50 \mathrm{ng} / \mathrm{g}$, and $100 \mathrm{ng} / \mathrm{g}$.

\section{Experimental animals and environmental conditions}

Sprague-Dawley rats were obtained from a specific pathogenfree colony at Samtako Co. (Osan, Republic of Korea). Forty-five rats ( 8 weeks old) of each sex were used for the in vivo toxicity study, and 45 male rats aged 7 weeks were used for the kinetic study. The animals were acclimated for 1 week before starting the experiments. Two rats were housed in each stainless wire mesh cage in a room maintained at a temperature of $23^{\circ} \mathrm{C} \pm 3^{\circ} \mathrm{C}$ and a relative humidity of $50 \% \pm 10 \%$ with artificial lighting from 08:00 to 20:00 and with 13-18 air changes per hour. Rats were provided tap water that had been sterilized by ultraviolet irradiation and commercial rodent chow (Samyang Feed, Wonju, Korea) ad libitum. The protocols for animals' study were approved by the Institutional Animal Care and Use Committee of Chonnam National University (approval number: CNU IACUCYB-2013-60), and the animals were cared for in accordance with the Guidelines for Animal Experiments of Chonnam National University.

\section{Comparative single oral dose toxicity study}

This study was conducted in compliance with the Test Guidelines of the Organization for Economic Cooperation and Development TG420 and 423. ${ }^{39,40}$ After a 7-day quarantine and acclimatization period, 45 healthy animals of each sex at 9 weeks of age were randomly assigned to nine experimental groups: four treatment groups receiving $312 \mathrm{mg} / \mathrm{kg}$, $625 \mathrm{mg} / \mathrm{kg}, 1,250 \mathrm{mg} / \mathrm{kg}$, and 2,500 mg/kg of $\mathrm{Cu} \mathrm{NPs}$, respectively; four treatment groups receiving $156 \mathrm{mg} / \mathrm{kg}$, $312 \mathrm{mg} / \mathrm{kg}, 625 \mathrm{mg} / \mathrm{kg}$, and $1,250 \mathrm{mg} / \mathrm{kg}$ of $\mathrm{Cu}$ ions, respectively; and one control group receiving 1\% HPMC vehicle alone. The dose levels of $\mathrm{Cu}$ NPs were selected based on the results of a preliminary study. Six rats of each sex were assigned two groups (three males and three females per group) and were administered 1,000 $\mathrm{mg} / \mathrm{kg}$ and $5,000 \mathrm{mg} / \mathrm{kg}$ of $\mathrm{Cu}$ NPs. All rats showed severe toxic symptoms at $5,000 \mathrm{mg} / \mathrm{kg}$, whereas no treatment-related effects were found at $1,000 \mathrm{mg} / \mathrm{kg}$. Thus, we selected $2,500 \mathrm{mg} / \mathrm{kg}$ as the highest dose level of $\mathrm{Cu}$ NPs. To compare their toxicity, dose levels of $\mathrm{Cu}$ ions were selected as overlapping with dose 
levels of $\mathrm{Cu}$ NPs. Each group consisted of five rats of each sex. The application volume $(10 \mathrm{~mL} / \mathrm{kg}$ body weight) was calculated based on the most recently recorded body weight of individual animals. Control rats received an equivalent volume of 1\% HPMC vehicle alone. Median lethal dose $\left(\mathrm{LD}_{50}\right)$ values of $\mathrm{Cu}$ NPs and $\mathrm{Cu}$ ions were calculated using Miller and Tainter's Probit method. ${ }^{41}$

Each animal was observed twice daily throughout test period for any clinical signs of toxicity or mortality. The body weight of each rat was measured on days $0,1,3,7$, and 14. At the scheduled necropsy, blood samples were collected from the vena cava under carbon dioxide $\left(\mathrm{CO}_{2}\right)$ anesthesia. Collected blood samples were placed into tubes for serum separation and incubated at room temperature within 90 minutes. Serum samples were collected by centrifugation at 3,000 rpm for 10 minutes. Serum samples were evaluated using a blood chemistry autoanalyzer (Dri-chem 4000i; Fujifilm, Tokyo, Japan) to determine the following: aspartate aminotransferase (AST), alanine aminotransferase (ALT), alkaline phosphatase, blood urea nitrogen, creatinine, creatine phosphokinase (CPK), total bilirubin, total cholesterol (TCHO), total protein, albumin, lactate dehydrogenase $(\mathrm{LDH})$, triglyceride $(\mathrm{TG})$, sodium $(\mathrm{Na})$, potassium $(\mathrm{K})$, and chloride $(\mathrm{Cl})$. After collecting blood samples, rats were sacrificed by exsanguination from the abdominal aorta and vena cava. All organs were removed, weighed, and examined for macroscopically visible lesions. The following organs were weighed: brain, thymus, heart, lung, liver, spleen, kidneys, adrenal glands, testes, seminal vesicles, prostates, epididymides, and ovaries. Relative weights were calculated based on the organ-to-body weight ratio. Histopathological evaluation was performed by fixing tissue in a $10 \%$ neutralbuffered formalin solution. The tissues were stained with hematoxylin and eosin for microscopic examination. All observations were made manually in a totally blinded manner using a light microscope with $\times 5, \times 10, \times 20$, and $\times 40$ objective lenses and $\mathrm{a} \times 100$ oil immersion lens.

\section{In vivo absorption, biodistribution, and excretion study}

After a 7-day quarantine and acclimatization period, 45 healthy male rats aged 8 weeks were randomly assigned to 15 groups (three rats per group). Seven treatment groups received a single oral dose of Cu NPs at $500 \mathrm{mg} / \mathrm{kg}$, another seven treatment groups received a single oral dose of $\mathrm{Cu}$ ions at $500 \mathrm{mg} / \mathrm{kg}$, and a vehicle control group received 1\% HPMC alone. In the single oral dose toxicity study, $\mathrm{Cu}$ ions at $625 \mathrm{mg} / \mathrm{kg}$ caused several clinical signs, including hematuria, paleness, piloerection, diarrhea, and death. Therefore, we selected $500 \mathrm{mg} / \mathrm{kg}$ of $\mathrm{Cu}$ NPs and $\mathrm{Cu}$ ions to evaluate the absorption, distribution, and excretion. Three animals in each group were sacrificed at 0 hour (control), 12 hours, 24 hours, 48 hours, 72 hours, 1 week, 2 weeks, and 4 weeks after treatment. Absorption of $\mathrm{Cu}$ in $\mathrm{Cu} \mathrm{NP}$ - and $\mathrm{Cu}$ ion-treated rats was determined from blood samples. To evaluate tissue distribution, tissue samples from the liver, kidneys, spleen, lung, heart, and brain were obtained and weighed. Excretion of $\mathrm{Cu}$ was measured using urine and feces samples. To collect urine and feces samples, three animals per groups were assigned to a metabolic cage for 3 hours before necropsy. The weighed blood, urine $(\sim 1 \mathrm{~g})$, and tissues $(\sim 0.1 \mathrm{~g})$ were digested with concentrated nitric acid overnight, and all samples were analyzed for elemental $\mathrm{Cu}$ and ICP-MS as described previously.

\section{Statistical analysis}

The numerical data were presented as mean \pm SD. All statistical comparisons were analyzed by one-way analysis of variance followed by Dunnett's multiple comparison test. A $P$-value of $<0.05$ was considered as statistically significant. Statistical analyses were performed using the GraphPad InStat Version 3.0 (GraphPad Software, Inc., La Jolla, CA, USA).

\section{Results}

\section{Physicochemical characterization of Cu NPs}

The morphology of $\mathrm{Cu}$ NPs was generally spherical shape confirmed by TEM and SEM analyses (Figure 1A-D). The size distribution of $\mathrm{Cu}$ NPs was characterized by TEM and dynamic light scattering. The average size of $\mathrm{Cu}$ NPs stated by the manufacturer was $25 \mathrm{~nm}$, but the actual size was $32.7 \pm 10.45 \mathrm{~nm}$ (300 counts) (Figure 1E). Dynamic light scattering measurements showed that $\mathrm{Cu}$ NPs were prone to aggregation/agglomeration and formed larger size of NPs in vehicle ( $\mathrm{pH}$ 6.5) and simulated intestinal conditions (pH 7.8) with a hydrodynamic diameter of $516.4 \pm 116.9 \mathrm{~nm}$ and $334.8 \pm 128.26 \mathrm{~nm}$, respectively (Figure $1 \mathrm{~F}$ and Table 1). However, the hydrodynamic diameter in simulated acidic conditions ( $\mathrm{pH} 1.5$ ) was not determined. $\mathrm{Cu}$ NPs powder consisted of $\mathrm{Cu} 98.15 \%$, silicon $1.52 \%$, and iron $0.33 \%$ as determined using energy-dispersive X-ray spectroscopy on the same images of TEM (data not shown). The specific surface area of $\mathrm{Cu}$ NPs was $14.7 \mathrm{~m}^{2} / \mathrm{g}$ as determined using Brunauer-Emmett-Teller methods. The zeta potential of the $\mathrm{Cu}$ NPs was 15.5 $\pm 0.82 \mathrm{mV}$ at $\mathrm{pH} 1.5,1.32 \pm 1.2 \mathrm{mV}$ at $\mathrm{pH}$ 6.5, 

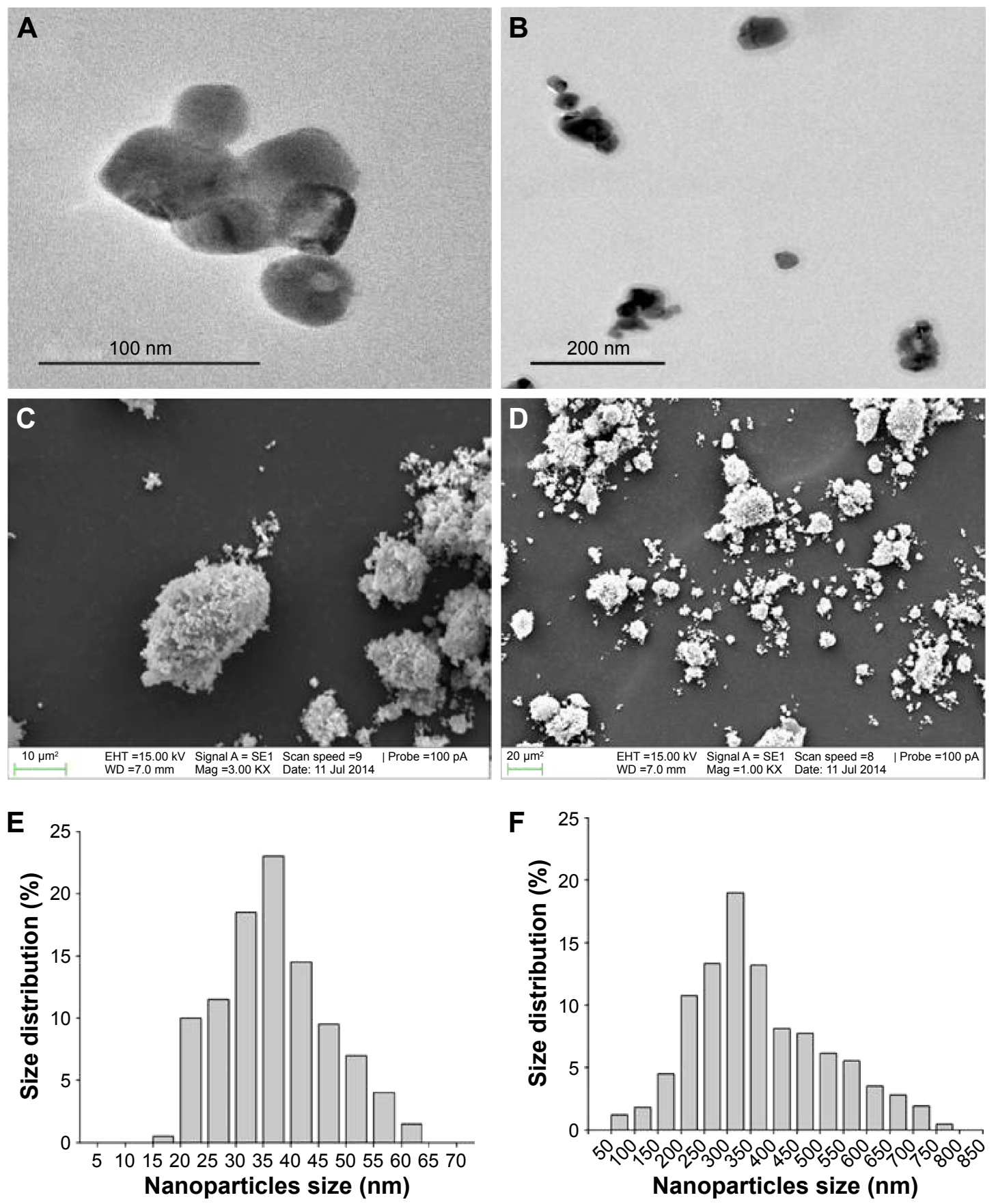

Figure I Morphology and size distribution of Cu NPs.

Notes: (A and B) TEM and (C and D) SEM images of Cu NPs. Size distribution of (E) actual size and (F) hydrodynamic size of Cu NPs (in deionized water, pH 7.8) is determined by TEM and DLS methods, respectively.

Abbreviations: Cu NPs, copper nanoparticles; DLS, dynamic light scattering; SEM, scanning electron microscopy; TEM, transmission electron microscopy.

Table I Physiochemical characterization of Cu NPs

\begin{tabular}{|c|c|c|c|c|c|c|c|}
\hline \multirow[t]{2}{*}{ Shape } & \multirow[t]{2}{*}{ Primary size $(\mathrm{nm})^{\mathrm{a}}$} & \multicolumn{2}{|c|}{ Hydrodynamic size $(\mathrm{nm})^{\mathrm{b}}$} & \multirow[t]{2}{*}{ Surface area $\left(\mathrm{m}^{2} / \mathrm{g}\right)^{c}$} & \multicolumn{3}{|c|}{ Zeta potential $(\mathrm{mV})^{\mathrm{d}}$} \\
\hline & & pH 6.5 & pH 7.8 & & pH I.5 & pH 6.5 & pH 7.8 \\
\hline Spherical & $33 \pm 9.8$ & $516 \pm 116.9$ & $334 \pm 128.3$ & 14.7 & $15.5 \pm 0.8$ & $1.32 \pm 1.2$ & $-6.2 \pm 0.2$ \\
\hline
\end{tabular}

Notes: aPrimary size of Cu NPs was measured by transmission electron microscopy (300 counts). b Nanoparticles were dispersed in deionized water and measured by a dynamic light scattering method. 'Surface area was measured by the Brunauer-Emmett-Teller method ( $\mathrm{N}_{2}$ gas). ${ }^{\mathrm{Z}} \mathrm{Zeta}$ potential was measured using electrophoretic light scattering method under $\mathrm{pH} \mathrm{I.5,} \mathrm{pH} 6.5$, and $\mathrm{pH} 7.8$ conditions.

Abbreviation: $\mathrm{Cu}$ NPs, copper nanoparticles. 
and $-6.2 \pm 0.2 \mathrm{mV}$ at $\mathrm{pH} 7.8$ (Table 1). The endotoxin levels of NP suspensions were not detected (data not shown).

\section{Dissolution of $\mathrm{Cu}$ NPs and $\mathrm{Cu}$ ions in gastric, vehicle, and intestinal conditions}

The dissolution of $\mathrm{Cu}$ NPs and $\mathrm{Cu}$ ions in biological conditions was confirmed by ICP-MS method. $\mathrm{Cu}$ NPs displayed minimal solubility in vehicle $(\mathrm{pH} 6.5)$ or basic $(\mathrm{pH} 7.8)$ conditions simulated intestinal environments. However, $\mathrm{Cu}$ NPs were dissolved mostly in acidic conditions ( $\mathrm{pH} 1.5$ ) with a solubility of $84.5 \%$ (Figure $2 \mathrm{~A}$ ). In contrast, $\mathrm{Cu}$ ions were dissolved completely in all three conditions within 5 minutes.

\section{In vivo kinetics of $\mathrm{Cu}$ NPs and $\mathrm{Cu}$ ions}

The in vivo kinetics of $\mathrm{Cu}$ NPs $(500 \mathrm{mg} / \mathrm{kg})$ and $\mathrm{Cu}$ ions (500 mg/kg, equivalent to $236 \mathrm{mg} / \mathrm{kg}$ based on $\mathrm{Cu}$ mass) were assessed using ICP-MS after oral administration, and then animals were sacrificed after 12 hours, 24 hours, 48 hours, 72 hours, 1 week, 2 weeks, and 4 weeks. The $\mathrm{Cu}$ content in the blood from $\mathrm{Cu}$ NP-treated groups was $51 \%$ lower $(1.94 \mu \mathrm{g} / \mathrm{g})$ than the highest level $(3.91 \mu \mathrm{g} / \mathrm{g})$ in $\mathrm{Cu}$ ion-treated rats at 12 hours (Figure 2B). The $\mathrm{Cu}$ NP-treated rats showed a highest level of the blood $\mathrm{Cu}(3.06 \mu \mathrm{g} / \mathrm{g})$ at 48 hours and a prolonged blood circulation time even at 4 weeks. The tissue distribution patterns of $\mathrm{Cu}$ also showed a similar trend as observed for blood $\mathrm{Cu}$ levels in $\mathrm{Cu} \mathrm{NP}$ - and $\mathrm{Cu}$ ion-treated rats. As shown in Figure 3, $\mathrm{Cu}$ NPs showed a gradual increase in $\mathrm{Cu}$ levels and peaked at 48 hours or
72 hours in tested organs. $\mathrm{Cu}$ NP-treated rats displayed high values of $\mathrm{Cu}$ levels in the liver $(516.5 \mu \mathrm{g} / \mathrm{g})$, kidneys $(54.7 \mu \mathrm{g} / \mathrm{g})$, heart $(47.6 \mu \mathrm{g} / \mathrm{g})$, and spleen $(38.1 \mu \mathrm{g} / \mathrm{g})$. After reaching a peak, $\mathrm{Cu}$ levels gradually decreased from these organs. In contrast, $\mathrm{Cu}$ ions displayed a rapid increase in concentration within 12 hours and reached higher $\mathrm{Cu}$ values at 24 hours in the tested organs than those of $\mathrm{Cu}$ NPs. The $\mathrm{Cu}$ concentration in the tested organs from $\mathrm{Cu}$ ion-treated rats also showed a gradual decrease after reaching the highest level, but $\mathrm{Cu}$ levels in liver sharply decreased. $\mathrm{Cu}$ levels in the urine of $\mathrm{Cu}$ NP-treated rats were lower $(1.42 \mu \mathrm{g} / \mathrm{g}$ at 72 hours) but gradually increased, relative to $\mathrm{Cu}$ ion-treated rats, which exhibited a sharp increase in $\mathrm{Cu}$ concentration and a twofold higher $\mathrm{Cu}$ content $(2.82 \mu \mathrm{g} / \mathrm{g}$ at 24 hours $)$ (Figure 4A). In contrast with urine excretion, $\mathrm{Cu}$ NP-treated rats showed 2.5-fold higher content of $\mathrm{Cu}$ in the excreted feces $(23,667 \mu \mathrm{g} / \mathrm{g}$ at 24 hours) (Figure 4B), whereas less $\mathrm{Cu}$ content was excreted in the feces of $\mathrm{Cu}$ ion-treated rats $(9,315 \mu \mathrm{g} / \mathrm{g}$ at 48 hours $)$.

\section{In vivo toxicity of $\mathrm{Cu}$ NPs and $\mathrm{Cu}$ ions} Mortality, body weight changes, and clinical signs In this study, the in vivo toxicity of $\mathrm{Cu}$ NPs was assessed at multiple dose levels $(312-2,500 \mathrm{mg} / \mathrm{kg}$ ) following oral administration. Their toxicity was compared with that of $\mathrm{Cu}$ ions at $156-1,250 \mathrm{mg} / \mathrm{kg}$. The $\mathrm{LD}_{50}$ value of $\mathrm{Cu} \mathrm{NPs}$ $(1,344 \mathrm{mg} / \mathrm{kg})$ in male rats was 2.1 -fold higher than that of $\mathrm{Cu}$ ions in male rats $(640 \mathrm{mg} / \mathrm{kg})$. In female rats, the oral $\mathrm{LD}_{50}$ value of Cu NPs $(2,411 \mathrm{mg} / \mathrm{kg})$ was 4.2 -fold higher than that

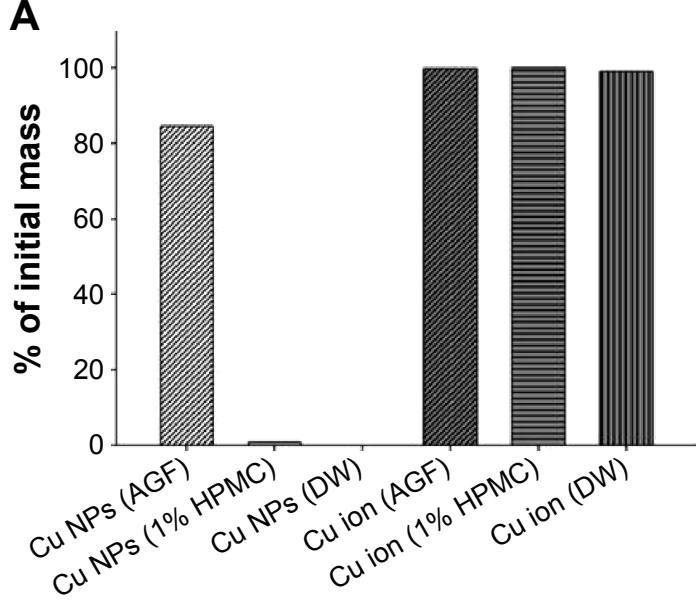

B

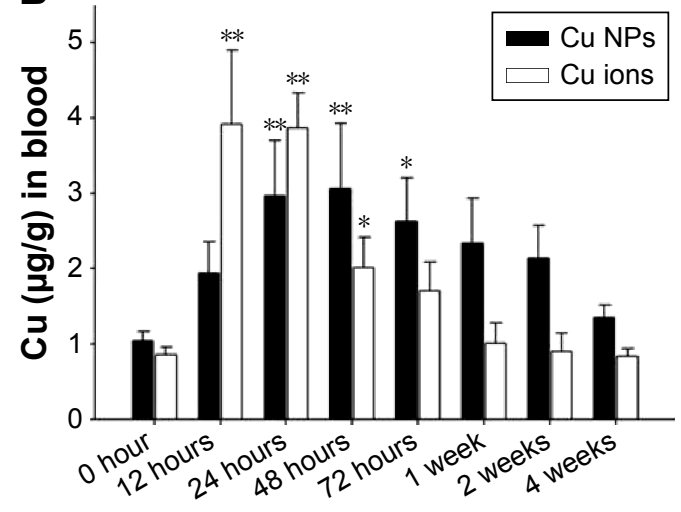

Figure 2 Dissolution of Cu NPs in biological conditions and systemic absorption of Cu from Cu NPs and Cu ions.

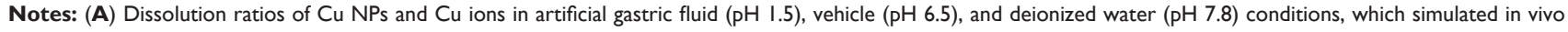
physiological conditions. Percentage of dissolution measured using ICP-MS after 24 hours incubation. (B) Absorption of Cu from Cu NP- and Cu ion-treated rats is measured at 0 hour (control), 12 hours, 24 hours, 48 hours, 72 hours, I week, 2 weeks, and 4 weeks after a single oral dose of $500 \mathrm{mg} / \mathrm{kg}$ each. Values are presented as mean \pm SD $(\mathrm{n}=3) . * P<0.05, * * P<0.01$ vs vehicle control. Cu ions, copper(II) chloride.

Abbreviations: AGF, artificial gastric fluid; DW, deionized water; Cu NPs, copper nanoparticles; HPMC, hydroxypropylmethylcellulose; ICP-MS, inductively coupled plasma mass spectrometry; SD, standard deviation. 
A

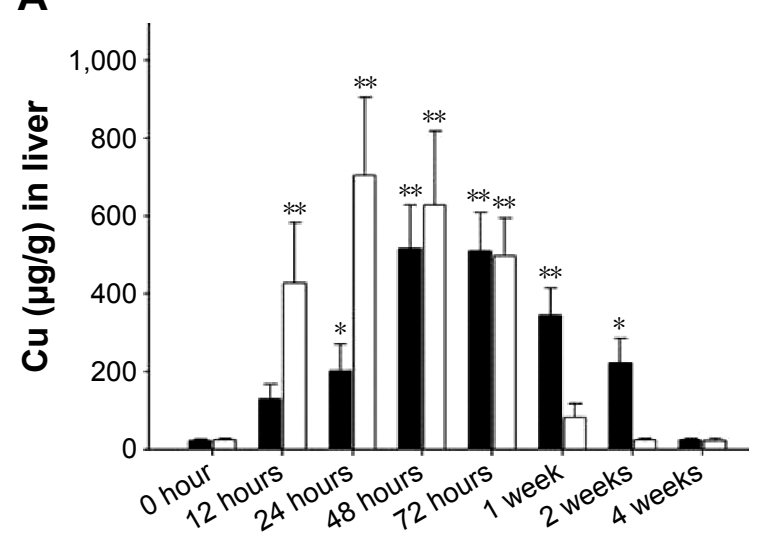

C

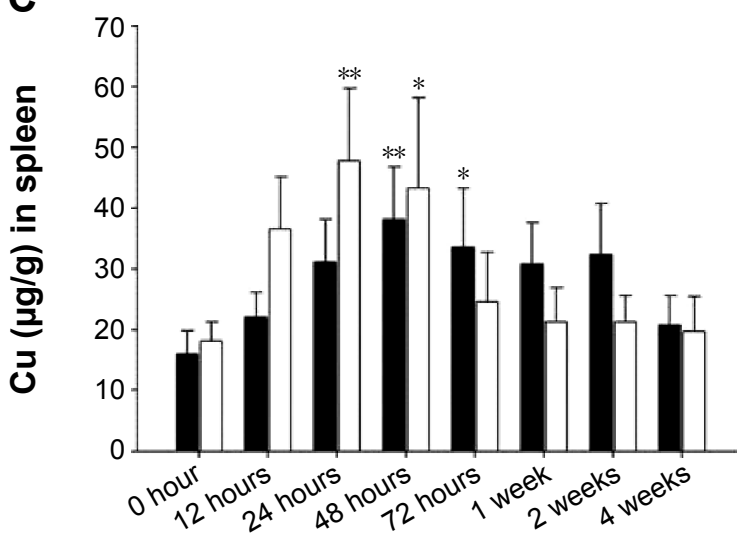

E

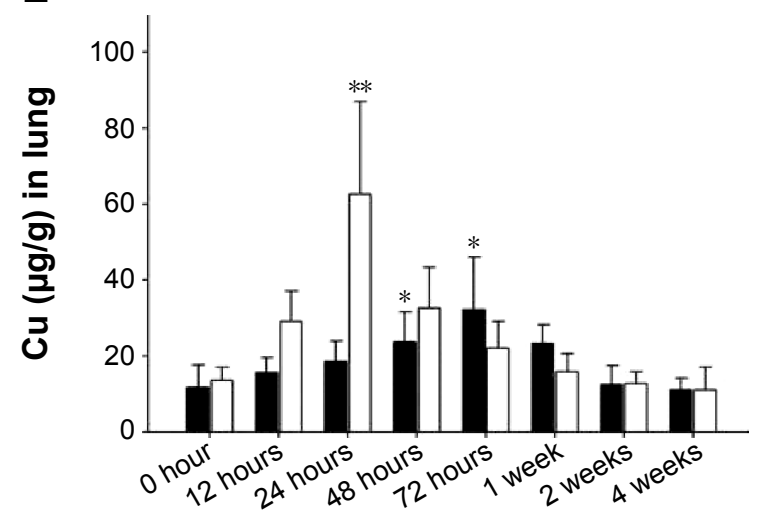

B

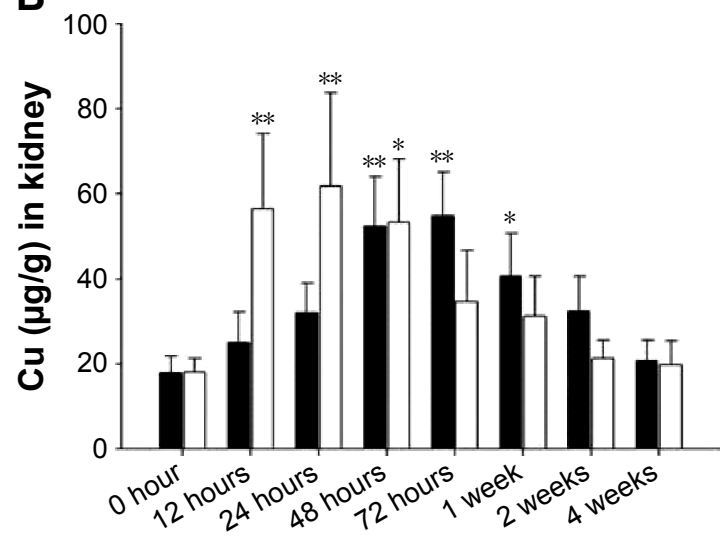

D

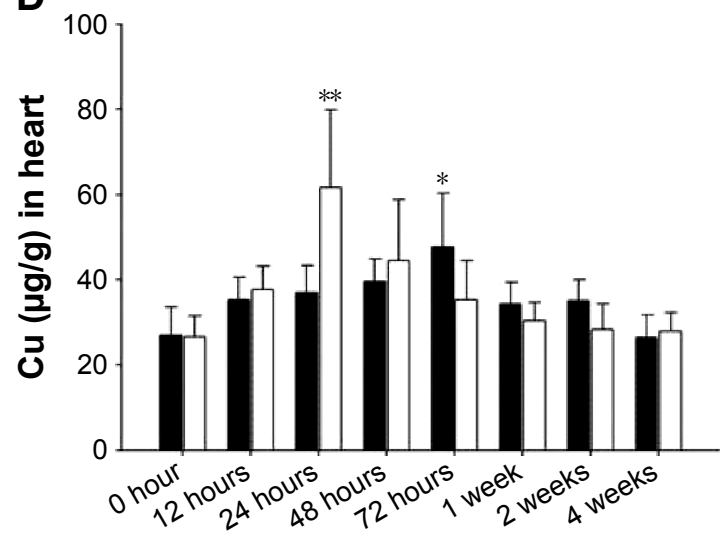

$\mathbf{F}$

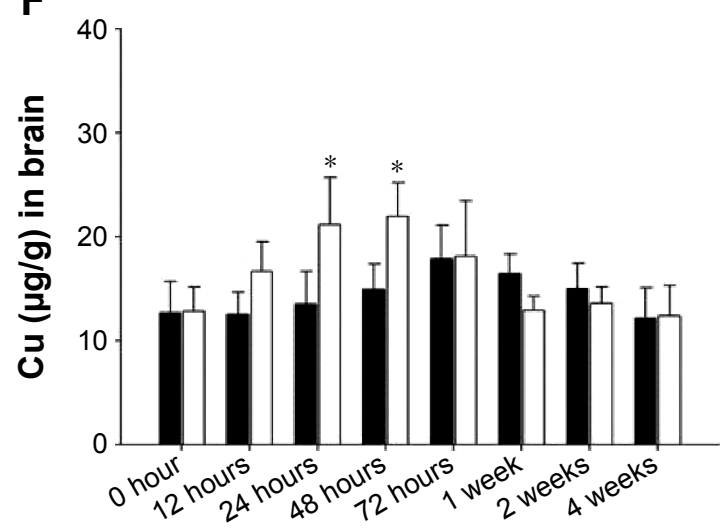

Cu NPs $\square$ Cu ions

Figure 3 Biodistribution of $\mathrm{Cu}$ from $\mathrm{Cu}$ NPs and $\mathrm{Cu}$ ions.

Notes: Cu levels in (A) liver, (B) kidney, (C) spleen, (D) heart, (E) lung, and (F) brain in the Cu NP- and Cu ion-treated rats are determined at 0 hour (control), 12 hours, 24 hours, 48 hours, 72 hours, I week, 2 weeks, and 4 weeks after a single oral dose of $500 \mathrm{mg} / \mathrm{kg}$ each. Values are presented as mean $\pm S D$ ( $=3$ ). $* P<0.05, * * P<0.01$ vs vehicle control. Cu ions, copper(II) chloride.

Abbreviations: Cu NPs, copper nanoparticles; SD, standard deviation.

of $\mathrm{Cu}$ ions $(571 \mathrm{mg} / \mathrm{kg}$ ) based on mortality (survival rate) (Figure 5A-D). In addition, $\mathrm{Cu}$ NP-treated male rats showed more severe clinical signs, less body weight gain, and lower $\mathrm{LD}_{50}$ value than those of female rats, but no sex differences were observed in $\mathrm{Cu}$ ion-treated groups in this study. A significant suppression in the body weight gain was observed in the
$1,250 \mathrm{mg} / \mathrm{kg}$ group of male rats and the 2,500 $\mathrm{mg} / \mathrm{kg}$ group of female rats treated with $\mathrm{Cu}$ NPs, while rats treated with $\mathrm{Cu}$ ions showed a slight/significant suppression in the body weight gain at $\geq 312 \mathrm{mg} / \mathrm{kg}$ for both sexes (Figure $5 \mathrm{E}-\mathrm{H}$ ). Treatment-related clinical signs, including soft feces, diarrhea, piloerection, hematuria, depression, paleness, prone 
A

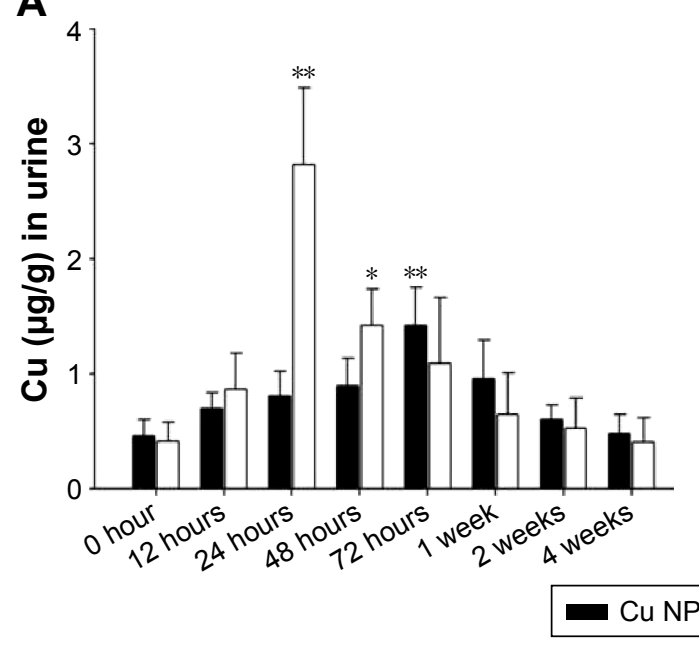

B

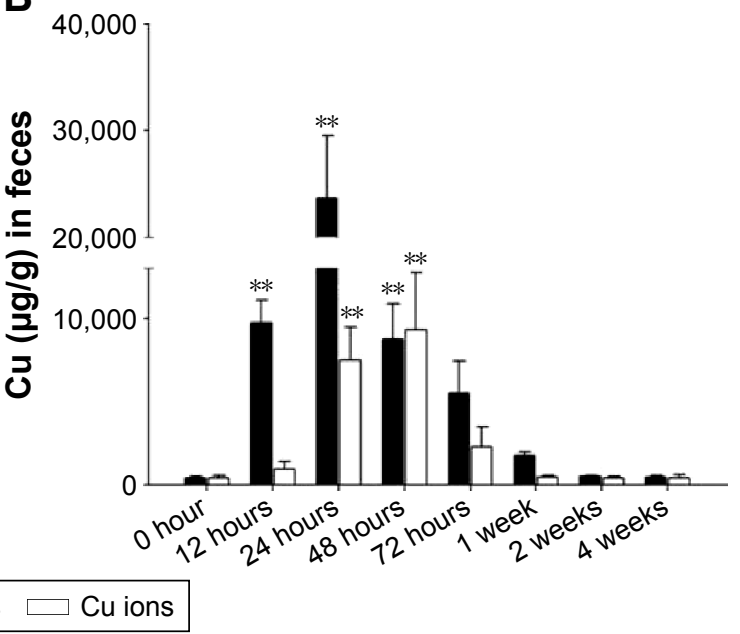

Figure 4 Excretion of $\mathrm{Cu}$ from $\mathrm{Cu}$ NPs and $\mathrm{Cu}$ ions.

Notes: $\mathrm{Cu}$ levels in (A) urine and (B) feces of Cu NP- and Cu ion-treated rats are measured at 0 hour (control), 12 hours, 24 hours, 48 hours, 72 hours, I week, 2 weeks, and 4 weeks after a single oral dose of $500 \mathrm{mg} / \mathrm{kg}$ each. Values are presented as mean $\pm S D(n=3)$. $* P<0.05$, $* * P<0.01$ vs vehicle control. Cu ions, copper(II) chloride. Abbreviations: Cu NPs, copper nanoparticles; SD, standard deviation.

position, nasal discharge, and death, were observed during the test period (data not shown). The rats treated with $\mathrm{Cu}$ NPs showed these signs at $\geq 1,250 \mathrm{mg} / \mathrm{kg}$, whereas $\mathrm{Cu}$ ion-treated rats showed similar toxic signs at $\geq 625 \mathrm{mg} / \mathrm{kg}$ of both sexes from test day 0 through day 10 .

\section{Histopathology}

The histopathological changes were observed in the liver, kidneys, and spleen of male rats treated with $\mathrm{Cu}$ NPs at $1,250 \mathrm{mg} / \mathrm{kg}$ and female rats treated with $\mathrm{Cu}$ NPs at $2,500 \mathrm{mg} / \mathrm{kg}$. These findings were also observed in both sexes of the rats treated with $\mathrm{Cu}$ ions at $625 \mathrm{mg} / \mathrm{kg}$. Cu NP-treated rats showed mild inflammatory cell infiltration and dilated sinusoids in the liver (Figure 6), mild-to-moderate degree of inflammatory cell infiltration, hyaline cast/cell debris in tubules, dilated tubules, atrophy of glomeruli in the kidneys, and multinucleated cells in the spleen. The incidence and severity of these findings in male rats were higher than those in female rats. These histopathological changes were also observed in the $\mathrm{Cu}$ ion-treated rats, except for the formation of multinucleated cells in the spleen.

\section{Serum biochemistry}

The serum biochemistry results for $\mathrm{Cu}$ NP- and $\mathrm{Cu}$ iontreated rats are presented in Figures 7 and 8. In the $\mathrm{Cu}$ NPtreated rats, the serum levels of AST, ALT, blood urea nitrogen, $\mathrm{TCHO}$, and $\mathrm{LDH}$ in male rats and $\mathrm{CPK}$ and $\mathrm{LDH}$ in female rats increased significantly, while $\mathrm{TG}, \mathrm{Na}$, and $\mathrm{Cl}$ levels of male rats decreased significantly in the $1,250 \mathrm{mg} / \mathrm{kg}$ group when compared with those of the control group.
A significant increase in the levels of AST, ALT, CPK, $\mathrm{TCHO}$, total protein, and $\mathrm{LDH}$ and a significant decrease in the levels of TG, $\mathrm{K}$, and $\mathrm{Cl}$ were also observed in female rats in the $2,500 \mathrm{mg} / \mathrm{kg}$ group (Figure 7 ). In the $\mathrm{Cu}$ ion-treated rats, CPK and LDH levels increased significantly, while TG levels decreased significantly in male rats in the $312 \mathrm{mg} / \mathrm{kg}$ group when compared with those of the control group. The serum levels of AST, alkaline phosphatase, CPK, and LDH in male rats and CPK and LDH levels in female rats increased significantly, whereas the TG levels in male rats decreased significantly in the $625 \mathrm{mg} / \mathrm{kg}$ group when compared with those of the control group (Figure 8).

\section{Organ weights}

Organ weights obtained in the study for male and female rats treated with $\mathrm{Cu}$ NPs are presented in Table S1. In male rats, the relative weight of seminal vesicles in the $625 \mathrm{mg} / \mathrm{kg}$ group decreased significantly when compared with that of control group. The absolute and relative weights of the kidneys and the relative weights of the liver, lung, and testes in the $1,250 \mathrm{mg} / \mathrm{kg}$ group increased significantly, whereas the absolute and relative weights of seminal vesicles and the absolute weights of the heart, thymus, and epididymides decreased significantly when compared with those of the control group. In female rats, the absolute and relative weights of thymus in the group treated with $\mathrm{Cu}$ NPs at $2,500 \mathrm{mg} / \mathrm{kg}$ decreased significantly, whereas the relative kidney weight increased significantly when compared with that of the control group. The organ weight changes of rats in the $\mathrm{Cu}$ ion-treated groups are presented in Table S2. The relative 
A
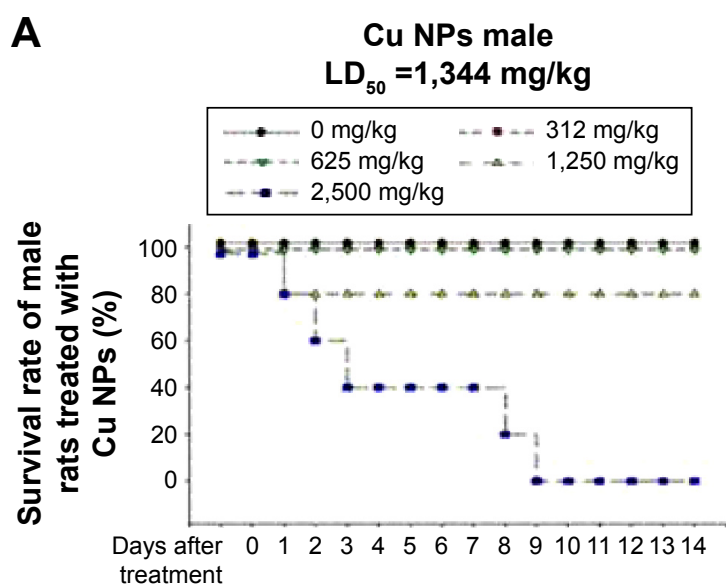

C
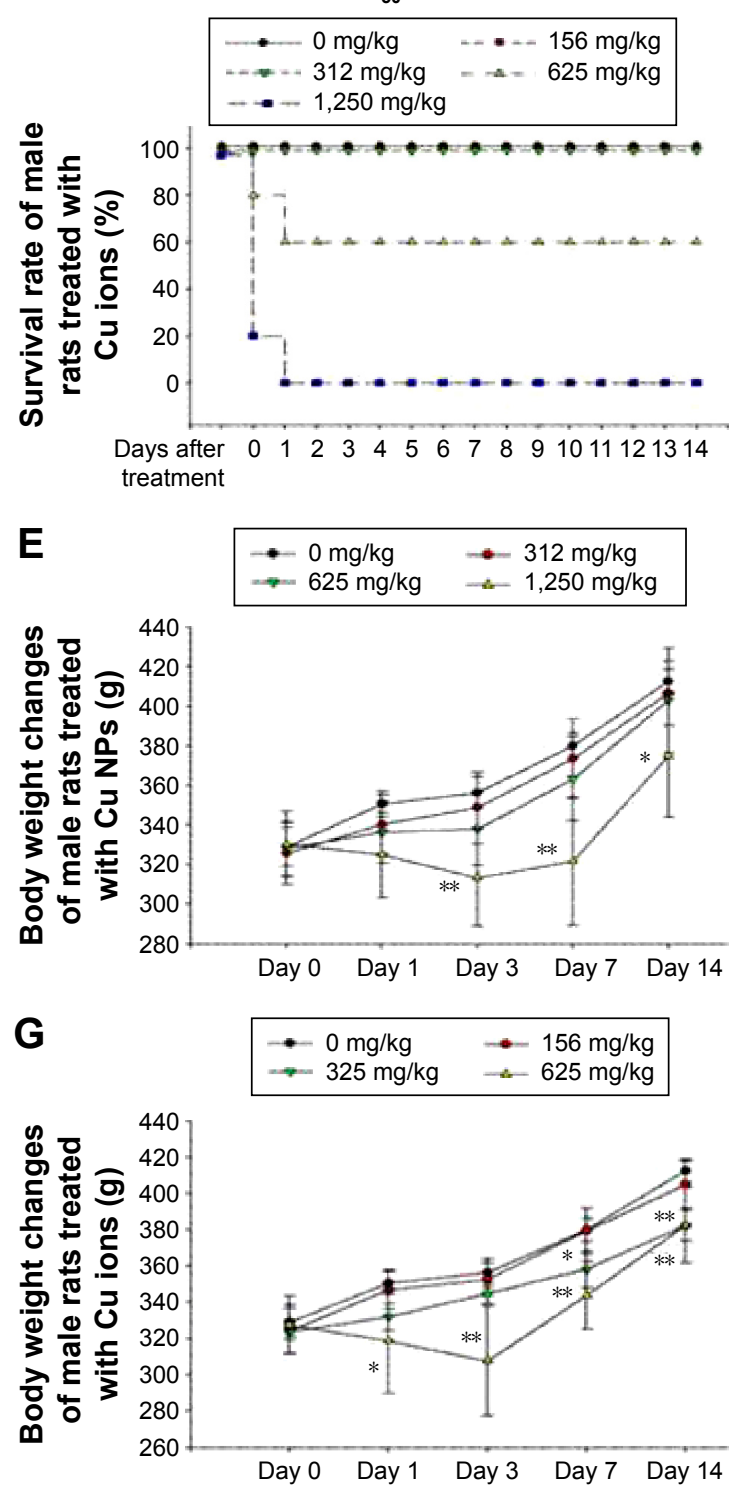

B

Cu NPs female $\mathrm{LD}_{50}=2,411 \mathrm{mg} / \mathrm{kg}$
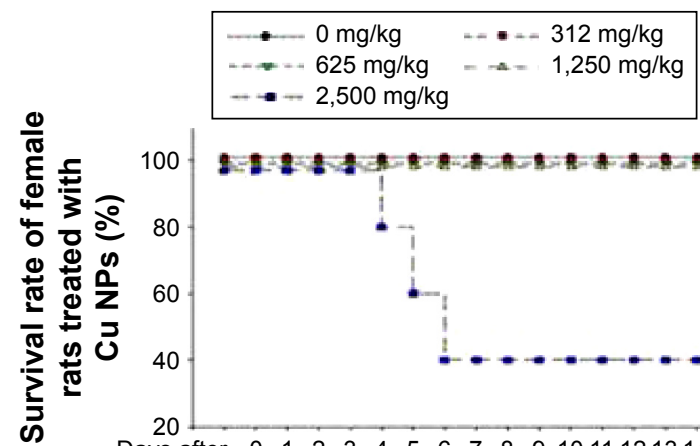

$-\rightarrow 2,500 \mathrm{mg} / \mathrm{kg}$
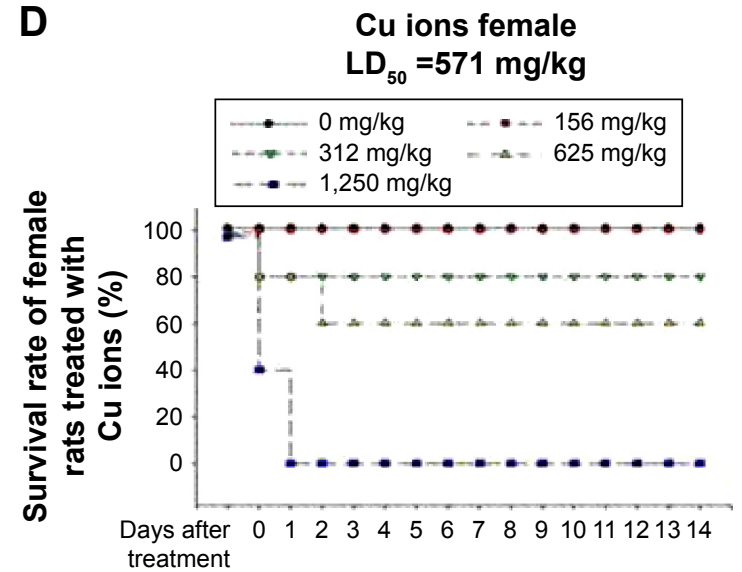

$\mathbf{F}$
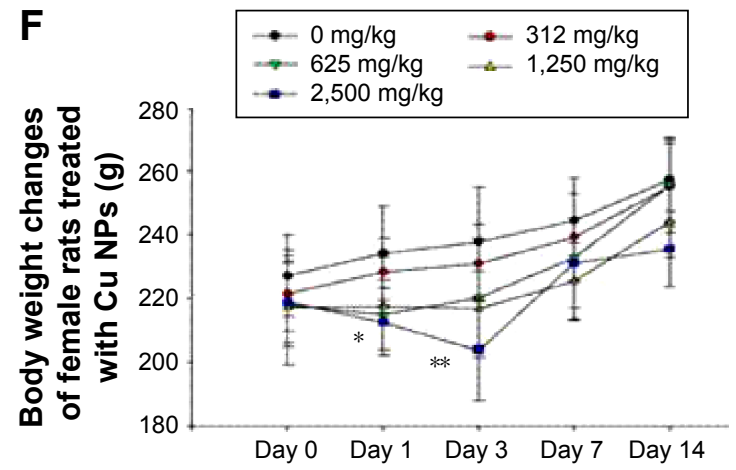

H $\quad \begin{array}{ll}-0 \mathrm{mg} / \mathrm{kg} & -156 \mathrm{mg} / \mathrm{kg} \\ -312 \mathrm{mg} / \mathrm{kg} & \longleftarrow 625 \mathrm{mg} / \mathrm{kg}\end{array}$

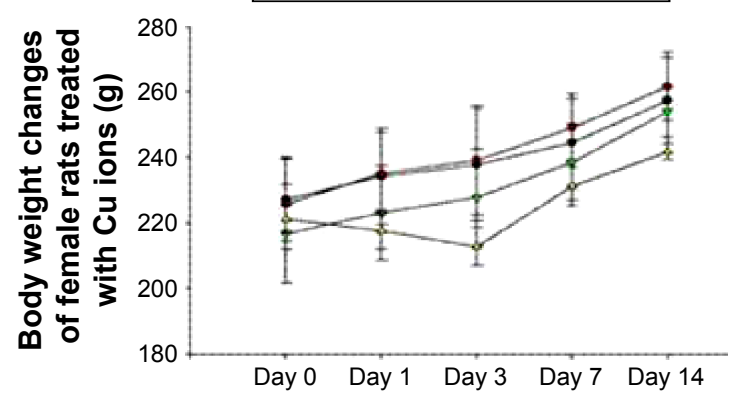

Figure 5 Mortality and body weight changes of Cu NP- and Cu ion-treated rats.

Notes: (A and B) Survival rate and (E and F) body weight changes of male and female rats, respectively, treated with single oral dose of Cu NPs (3I2-2,500 mg/kg). (C and $\mathbf{D})$ Survival rate and ( $\mathbf{G}$ and $\mathbf{H})$ body weight changes of male and female rats, respectively, treated with Cu ions (I56-I,250 mg/kg). Values are presented as mean \pm SD. $* P<0.05, * * P<0.01$ vs vehicle control. Cu ions, copper(II) chloride.

Abbreviations: Cu NPs, copper nanoparticles; $\mathrm{LD}_{50}$, median lethal dose; SD, standard deviation. 

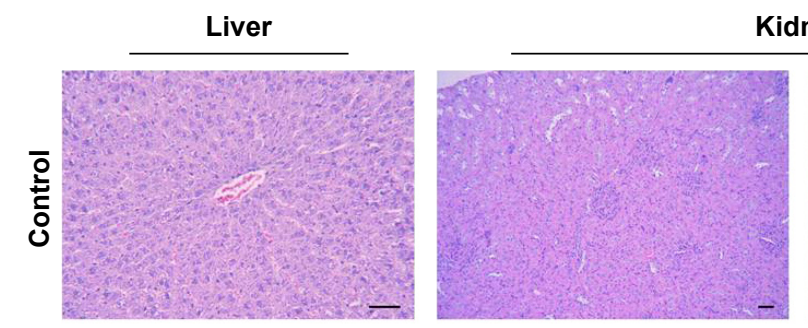

Kidney
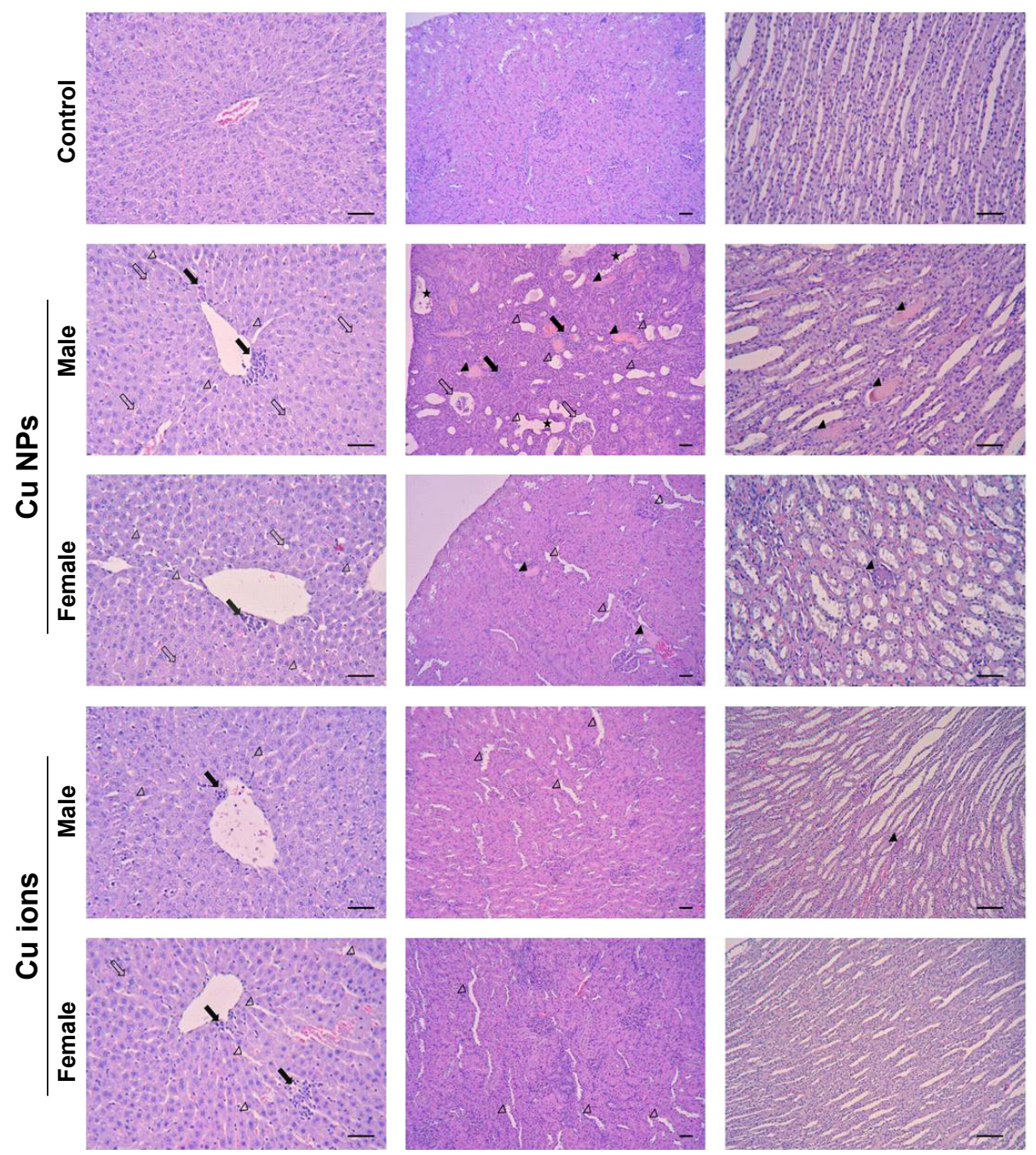
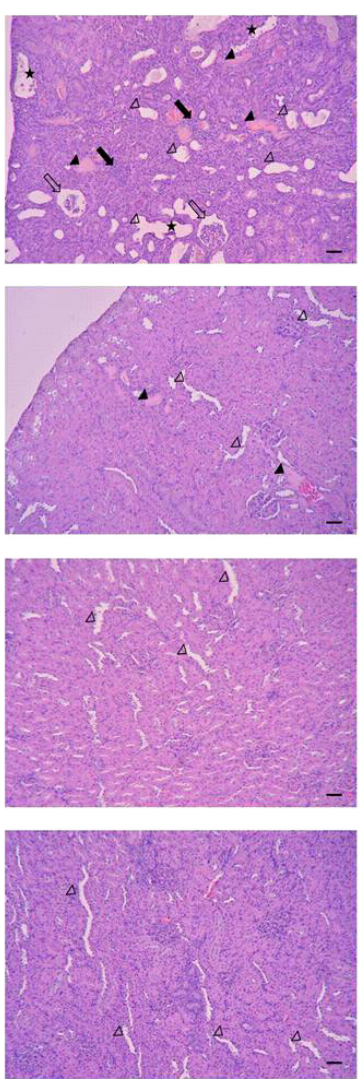
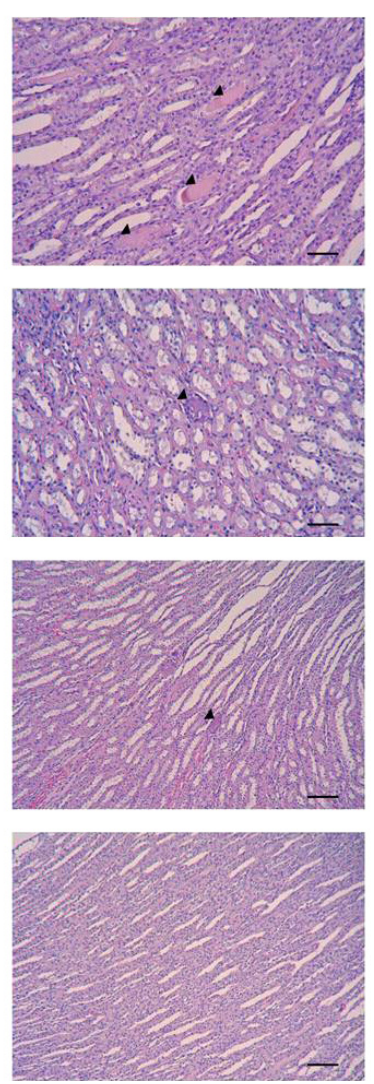
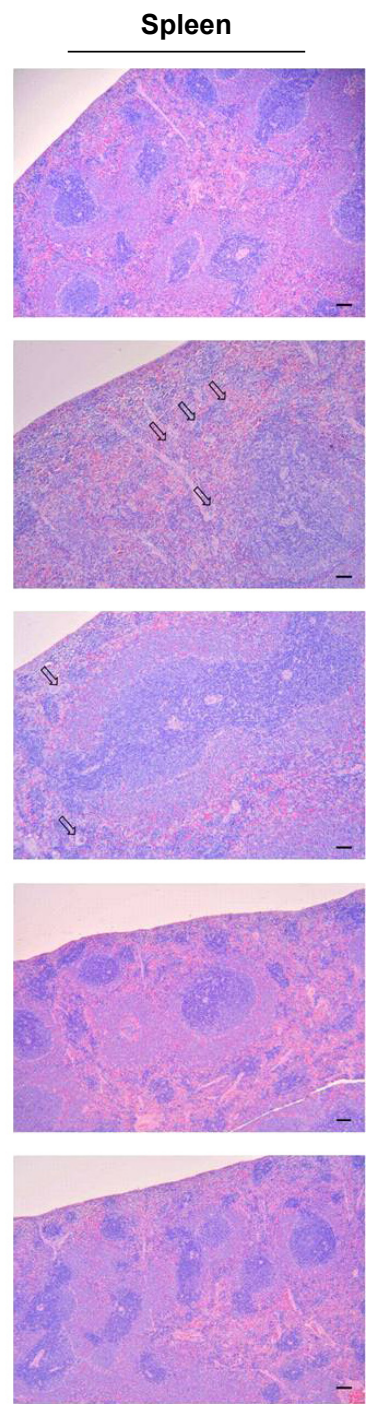

Figure 6 Histopathological results from the liver, kidney, and spleen of rats treated with Cu NPs and Cu ions.

Notes: The liver from rats treated with Cu NPs (males for $1,250 \mathrm{mg} / \mathrm{kg}$ and females for $2,500 \mathrm{mg} / \mathrm{kg}$ ) shows mild inflammatory cell infiltration (closed arrows), vacuolation (open arrows), and sinusoid dilation (open arrowheads). The rats treated with $\mathrm{Cu}$ ions show similar histopathological alterations at $625 \mathrm{mg} / \mathrm{kg}$ in both sexes ( $\times 200$ ). The histological changes of kidneys from rats treated with Cu NPs include inflammatory cell infiltration (closed arrows), hyaline cast (closed arrowheads) and cell debris (asterisks) in tubules, dilated tubules (open arrowheads), and atrophy of glomeruli (open arrows). Kidneys treated with Cu ions exhibit mild dilated tubules and cast in tubules (cortex, $\times 100$; medulla, $\times 200$ ). The spleen of rats treated with Cu NPs shows mild decrease in cellularity in white pulp and increase in multinucleated giant cells (megakaryocytes; open arrows). Spleen of rats treated with $\mathrm{Cu}$ ions has no histological changes $(\times 100)$. Hematoxylin and eosin stain. Scale bar $=50 \mu \mathrm{m}$. Cu ions, copper(II) chloride.

Abbreviation: Cu NPs, copper nanoparticles.

weights of kidneys in male rats in the group treated with $\mathrm{Cu}$ ions at $625 \mathrm{mg} / \mathrm{kg}$ increased significantly when compared with that of the control group. In female rats, the absolute and relative weights of the spleen in the group treated with $\mathrm{Cu}$ ions at $625 \mathrm{mg} / \mathrm{kg}$ decreased significantly, whereas the relative weights of thymus and kidneys increased significantly when compared with those of the control group.

\section{Discussion}

Nanomaterials have recently received increasing attention because of their distinctive physicochemical properties and great prospects for use in a wide range of applications. However, their unique physicochemical, electrical, optical, and biological properties may dominate their toxicological behavior in vivo. ${ }^{4,42}$ In addition, physiological milieus influence the interaction of biological systems with NPs and can determine the fate and biosafety of NPs. ${ }^{7}$ Thus, comprehensive characterization of the NPs in physiological conditions is a fundamental step prior to assessing the in vivo toxicity of $\mathrm{Cu}$ NPs. The hydrodynamic diameter and zeta potential of $\mathrm{Cu}$ NPs indicated that $\mathrm{Cu}$ NPs have a tendency to aggregate/agglomerate in vehicle $(\mathrm{pH} 6.5)$ and simulated intestinal ( $\mathrm{pH} 7.8)$ conditions. However, their hydrodynamic diameter in simulated acidic conditions $(\mathrm{pH}$ 1.5) could not be determined, since $\mathrm{Cu}$ NPs rapidly dissolved in acidic conditions and the particle number of Cu NPs was 

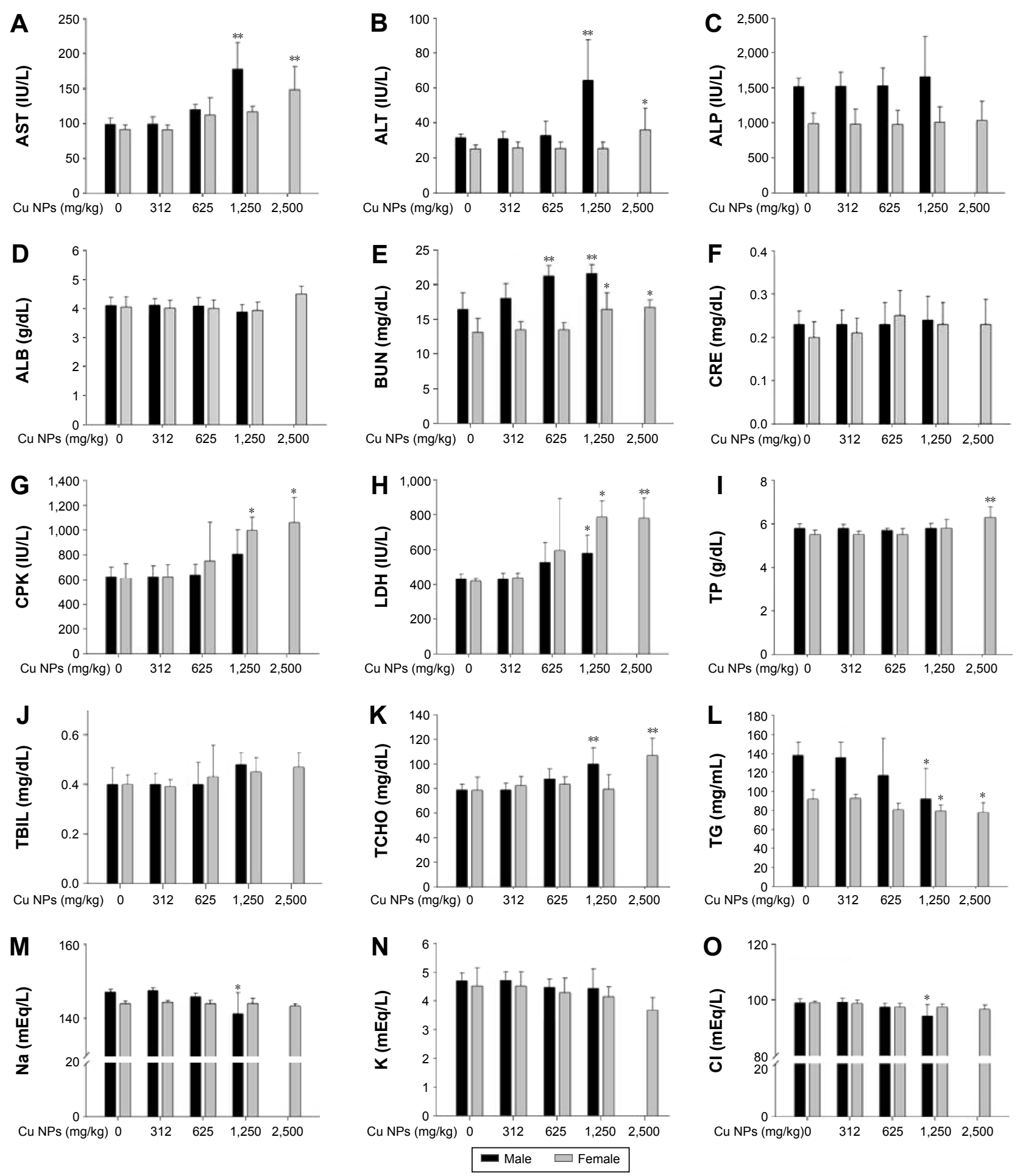

Figure 7 Serum biochemical changes of Cu NP-treated rats at dose levels of $0 \mathrm{mg} / \mathrm{kg}, 312 \mathrm{mg} / \mathrm{kg}, 625 \mathrm{mg} / \mathrm{kg}, 1,250 \mathrm{mg} / \mathrm{kg}$, and 2,500 mg/kg.

Notes: The bar graphs present serum biochemical changes of Cu NP (A-O)-treated male and female rats. Values are presented as mean \pm SD. $* P<0.05$, $* * P<0.0$ I vs vehicle control.

Abbreviations: ALB, albumin; ALP, alkaline phosphatase; ALT, alanine aminotransferase; AST, aspartate aminotransferase; BUN, blood urea nitrogen; CPK, creatine phosphokinase; CRE, creatinine; Cu NPs, copper nanoparticles; LDH, lactate dehydrogenase; TBIL, total bilirubin; TCHO, total cholesterol; TG, triglyceride; TP, total protein; $\mathrm{SD}$, standard deviation.

not enough to determine the hydrodynamic diameter by dynamic light scattering analysis. The current paradigm for toxicity of metal nanomaterials is the release of toxic ions when thermodynamic properties of a material favor particle dissolution in a suspending medium or biological milieu. ${ }^{43,44}$ The dissolution of NPs and release of potential toxic ions are dependent on $\mathrm{pH}$, composition, and exposure duration. ${ }^{45}$ The dissolution in gastrointestinal fluids may help 

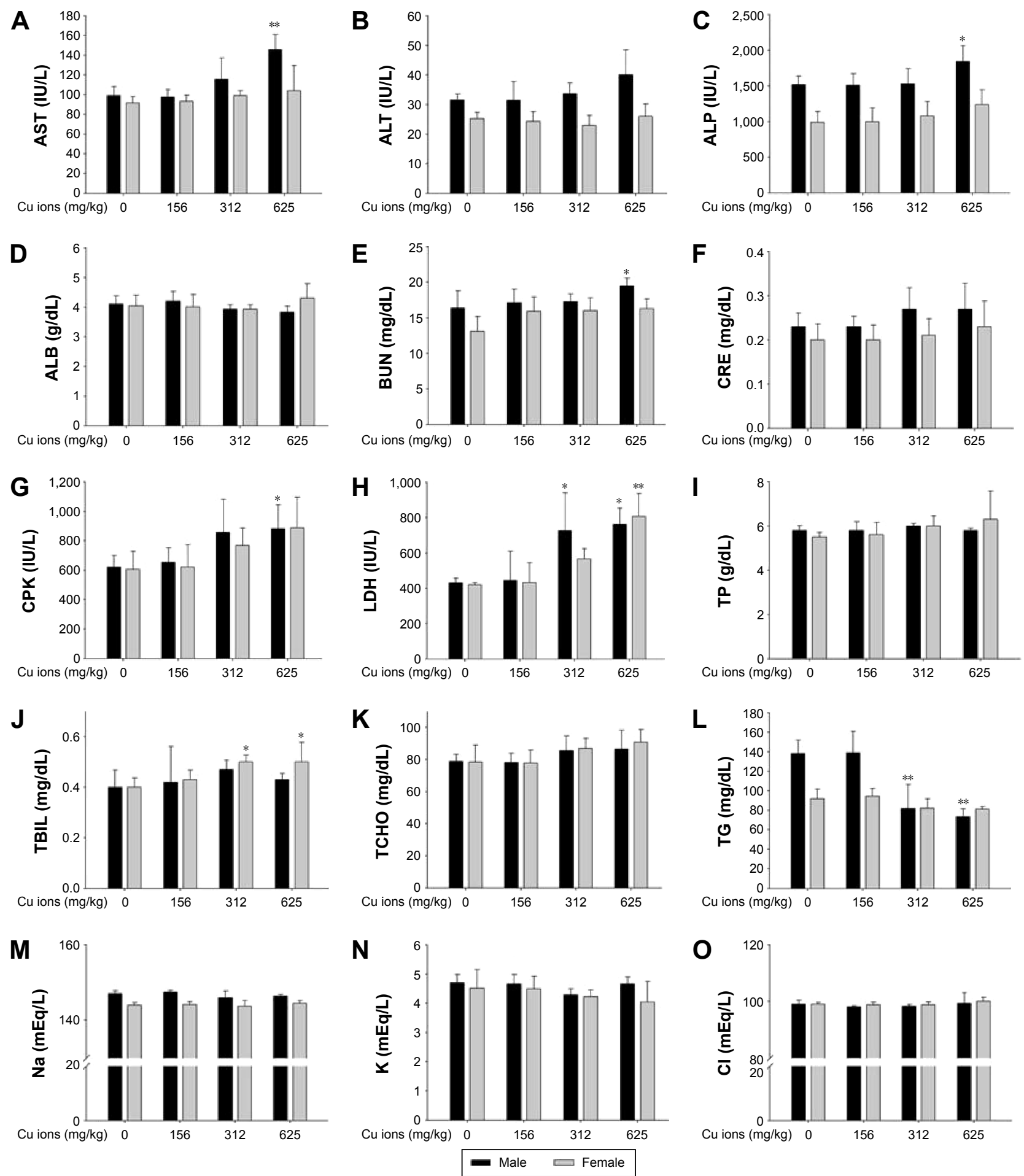

Figure 8 Serum biochemical changes of Cu ion-treated rats at dose levels of $0 \mathrm{mg} / \mathrm{kg}, 156 \mathrm{mg} / \mathrm{kg}, 312 \mathrm{mg} / \mathrm{kg}$, and $625 \mathrm{mg} / \mathrm{kg}$.

Notes: The bar graphs show serum biochemical changes of $\mathrm{Cu}$ ion $(\mathbf{A}-\mathbf{O})$-treated male and female rats. Values are presented as mean $\pm \mathrm{SD}$. $* P<0.05$, $* * P<0.0 \mathrm{I}$ vs vehicle control. Cu ions, copper(II) chloride.

Abbreviations: ALB, albumin; ALP, alkaline phosphatase; ALT, alanine aminotransferase; AST, aspartate aminotransferase; BUN, blood urea nitrogen; CPK, creatine phosphokinase; CRE, creatinine; LDH, lactate dehydrogenase; TBIL, total bilirubin; TCHO, total cholesterol; TG, triglyceride; TP, total protein; SD, standard deviation.

predict the uptake and blood concentrations. ${ }^{46}$ It has been reported that $\mathrm{Cu}$ NPs or $\mathrm{CuO}$ NPs have high solubility in acidic milieu ( $\mathrm{pH} 5.5$ ) with high positive zeta potential..$^{25,35}$ Thus, the high dissolution and zeta potential of $\mathrm{Cu}$ NPs in acidic conditions reflect a considerable interaction of $\mathrm{Cu}$ NPs within acidic milieu simulating the stomach.

In vivo biodistribution of $\mathrm{Cu}$ NPs can provide essential information regarding their absorption, accumulation sites, and 
clearance. Although the kinetics in serum, kidney, and urine of $\mathrm{Cu}$ NPs or $\mathrm{Cu}$ ions in mice have been reported, ${ }^{35}$ there were limited data for biokinetics after $\mathrm{Cu}$ NPs on $\mathrm{Cu}$ ions exposure. Thus, we explored the further evaluation of the tissue biodistribution in the liver, spleen, lung, brain, and heart for 4-week period after single oral exposure. In the multistep process of NPs' uptake, the physicochemical features of NPs (particle size, surface area, aggregation state, surface charge, etc) are likely to influence the degree of absorption and effects of administered NPs. ${ }^{47,48}$ The rate of dissolution also affects the absorption and biological response of NPs. ${ }^{46}$ Comparative kinetic study of zinc oxide $(\mathrm{ZnO})$ and titanium dioxide $\left(\mathrm{TiO}_{2}\right)$ NPs revealed that the higher absorption and more extensive organ distribution of ZnO NPs might be due to their higher dissolution rate in acidic gastric fluid than $\mathrm{TiO}_{2} \mathrm{NPs}$, which have minimal dissolution in acidic milieu. ${ }^{49}$ It has been reported that $\mathrm{Cu}$ levels in serum and kidney of nano- $\mathrm{Cu}(75 \mathrm{mg} / \mathrm{kg})$ treated mice are elevated at 24 hours and remain at the higher level until 72 hours when compared to equivalent $\mathrm{Cu}$ mass of ion- $\mathrm{Cu}(147.6 \mathrm{mg} / \mathrm{kg}$, equivalent $70 \mathrm{mg} / \mathrm{kg}$ on Cu mass $) .{ }^{35}$ Considering the $\mathrm{Cu}$ mass of $\mathrm{Cu}$ ions $(236 \mathrm{mg} / \mathrm{kg}, 47.2 \%$ of $500 \mathrm{mg} / \mathrm{kg}$ ) used in this study, the absorbed $\mathrm{Cu}$ levels of $\mathrm{Cu}$ NP-treated groups showed slow increase and low uptake when compared with those of $\mathrm{Cu}$ ion-treated rats. Tissue distribution of $\mathrm{Cu}$ was similar to the absorption rate of $\mathrm{Cu}$ from $\mathrm{Cu}$ NPs and $\mathrm{Cu}$ ions. The highest levels of $\mathrm{Cu}$ in tested organs of $\mathrm{Cu}$ NP-treated rats were $15 \%-25 \%$ lower than those of $\mathrm{Cu}$ ions. The complete dissolution of $\mathrm{Cu}$ ions in vehicle $\mathrm{pH}$ 6.5) suggested that dissociated $\mathrm{Cu}$ ions in suspension were readily absorbed from gastrointestinal tract. Eventually, $\mathrm{Cu}$ level in the blood and tested organs of $\mathrm{Cu}$ ions rapidly reached the highest level, which was much higher than that of $\mathrm{Cu}$ NPs at early time points. $\mathrm{Cu}$ NPs can react dramatically with hydrogen ions $\left(\mathrm{H}^{+}\right)$of gastric juice and transform into ionic states. ${ }^{17,35}$ Because the $\mathrm{pH}$ of gastric fluid is between 1.5 and 2.0, the NPs may be dissolved in the stomach, and the dissociated $\mathrm{Cu}$ ions are able to be absorbed into the systemic circulation following oral administration. However, $\mathrm{Cu}$ NPs were scarcely dissolved and easily aggregated/agglomerated with low zeta potential in vehicle solution, which affected the dissolution of $\mathrm{Cu}$ NPs in gastric environment when administered orally. In addition, high dose of NPs increases the potential for aggregation, subsequently decreasing the absorption of NPs from gastrointestinal tract. ${ }^{46}$ Thus, aggregation of NPs in gastrointestinal tract can lead to decreased absorption. ${ }^{50,51}$ In view of this point, low and delayed uptake of $\mathrm{Cu}$ dissociated from $\mathrm{Cu}$ NPs may be due to increased aggregation and subsequent decreased dissolution of $\mathrm{Cu}$ NPs in physiological milieu that attributed to slow increase and less accumulation of $\mathrm{Cu}$ in organs. However, further studies will be necessary to investigate whether $\mathrm{Cu}$ NPs are absorbed as an entity under intestinal conditions or whether dissolved $\mathrm{Cu}$ ions are redeposited in the tissues.

Ingested $\mathrm{Cu}$ ions are mainly metabolized in the liver, and the major excretory route is liver/bile. ${ }^{52,53}$ As described earlier, $\mathrm{Cu}$ NPs react with $\mathrm{H}^{+}$of gastric juice and can be transformed into ionic sates when they are administered orally. ${ }^{17}$ After gastric emptying, the dissociation of $\mathrm{Cu}$ NPs is inhibited in basic milieu of small intestine, and then unabsorbed NPs are excreted in feces. ${ }^{35}$ Thus, our findings suggest that most of the absorbed $\mathrm{Cu}$ dissociated from $\mathrm{Cu}$ NPs or unabsorbed $\mathrm{Cu}$ NPs is mainly excreted through feces, while a small amount of $\mathrm{Cu}$ NPs is eliminated through urine.

The oral $\mathrm{LD}_{50}$ value of nano- $\mathrm{Cu}(23.5 \mathrm{~nm})$ is determined as $413 \mathrm{mg} / \mathrm{kg}$, which is 3.8 -fold higher than that of ion- $\mathrm{Cu}$ $(110 \mathrm{mg} / \mathrm{kg})$ in mice. ${ }^{17}$ We confirmed that $\mathrm{Cu}$ NPs exerted lower toxic responses compared with $\mathrm{Cu}$ ions. The toxic responses of $\mathrm{Cu}$ NPs also showed clear sex-related difference at dose levels that produced changes in serum biochemistry, histology, and organ weights. As the males can secrete more $\mathrm{H}^{+}$in stomach, more nano- $\mathrm{Cu}$ could be transformed into $\mathrm{Cu}$ ions in the male mice than in female mice. Thus, male mice exhibited more severe toxic symptoms than female mice after exposure to the same mass of nano- $\mathrm{Cu} .{ }^{17}$ These findings suggested that toxic effects of $\mathrm{Cu}$ NPs could be attributed to their transformation into ionic $\mathrm{Cu}$ states and $\mathrm{Cu}$ NPs were more easily transformed into $\mathrm{Cu}$ ions in male rats than in female rats. Thus, the different dissolution of $\mathrm{Cu}$ NPs and $\mathrm{Cu}$ ions in physiological conditions can probably explain the differences in in vivo toxicity profiles between $\mathrm{Cu} \mathrm{NPs}$ and $\mathrm{Cu}$ ions. However, further study is necessary to determine the exact mechanism of sex-related difference in toxicity of Cu NPs.

Single or short-term exposure to $\mathrm{Cu}$ NPs can cause morphological changes in the liver, kidneys, and spleen with various histopathological alterations. ${ }^{17,33}$ Repeated oral administration of $\mathrm{Cu}$ NPs to rats at $200 \mathrm{mg} / \mathrm{kg} / \mathrm{d}$ for 5 days caused necrosis of hepatocytes and renal proximal tubules accompanied with hepatic and renal dysfunction. ${ }^{33,34}$ In this study, a single oral dose of $\mathrm{Cu}$ NPs at $1,250 \mathrm{mg} / \mathrm{kg}$ in male rats and 2,500 $\mathrm{mg} / \mathrm{kg}$ in female rats caused significant adverse effects on the histology of kidneys, liver, and spleen but not heart and lung. These histopathological changes were well supported by organ weight changes, including increased liver and kidney weights and decreased spleen weight. Additionally, the increment or decrement in serum biochemical levels exhibited a clear dose-response relationship and was consistent with the damage of kidney and liver. These changes were also observed in $\mathrm{Cu}$ ion-treated rats at $\geq 312 \mathrm{mg} / \mathrm{kg}$ in 
both sexes. Given that the accumulated $\mathrm{Cu}$ in organs may act as toxic reservoirs, these findings indicated that major organs affected by the $\mathrm{Cu}$ NPs in rats were liver, kidneys, and spleen, which were well correlated with the biodistribution of $\mathrm{Cu}$. Collectively, these results support the hypothesis that toxicity profiles and kinetics of $\mathrm{Cu}$ NPs are closely associated with their dissolution rate in the physiological milieu, which involved a clear sex difference and less toxic response for $\mathrm{Cu}$ NPs compared to $\mathrm{Cu}$ ions.

\section{Conclusion}

Physicochemical analysis suggests that $\mathrm{Cu}$ NPs in vehicle or simulated intestinal milieu show a tendency of aggregation/agglomeration with low solubility. However, Cu NPs are dissolved in acidic conditions with high positive charge but less dissolution compared with $\mathrm{Cu}$ ions. These findings imply that interaction between physicochemical characters of NPs and biological system may affect their toxicity and behavior in vivo. Kinetic study demonstrates that $\mathrm{Cu}$ levels in blood and tested organs from $\mathrm{Cu}$ NPs show delayed increase and lower increase than that observed for $\mathrm{Cu}$ ions. However, absorbed or accumulated $\mathrm{Cu}$ from $\mathrm{Cu}$ NPs exhibits slower decrease in blood and tested organs than $\mathrm{Cu}$ ions. Unabsorbed $\mathrm{Cu}$ NPs or absorbed $\mathrm{Cu}$ dissociated from $\mathrm{Cu}$ NPs was primarily eliminated through feces. In vivo toxicity of $\mathrm{Cu}$ NPs occurs at much higher doses than that of $\mathrm{Cu}$ ions to elicit similar response with obvious sex-related differences. Furthermore, $\mathrm{Cu}$ NPs cause systemic toxic effects with functional and morphological changes in the liver, kidneys, and spleen. Collectively, by comparison with their ionic form, in vivo toxicity of $\mathrm{Cu}$ NPs is most likely correlated with their solubility in the physiological milieu and their biodistribution.

\section{Acknowledgments}

This research was supported by Basic Science Research Program through the National Research Foundation of Korea funded by the Ministry of Education, Science and Technology (NRF-2013R1A1A2010835). The animal experiment in this study was supported by the Animal Medical Institute of Chonnam National University.

\section{Disclosure}

The authors report no conflicts of interest in this work.

\section{References}

1. Bhattacharya S, Alkharfy KM, Janardhanan R, Mukhopadhyay D. Nanomedicine: pharmacological perspectives. Nanotechnol Rev. 2012; 1(3):235-253.
2. Bouwmeester H, Dekkers S, Noordam MY, et al. Review of health safety aspects of nanotechnologies in food production. Regul Toxicol Pharmacol. 2009;53(1):52-62.

3. Suh WH, Suslick KS, Stucky GD, Suh YH. Nanotechnology, nanotoxicology, and neuroscience. Prog Neurobiol. 2009;87(3):133-170.

4. Aillon KL, Xie Y, El-Gendy N, Berkland CJ, Forrest ML. Effects of nanomaterials physicochemical properties on in vivo toxicity. Adv Drug Deliv Rev. 2009;61(6):457-466.

5. Kang M, Lim CH, Han JH. Comparison of toxicity and deposition of nano-sized carbon black aerosol prepared with or without dispersing sonication. Toxicol Res. 2013;29(2):121-127.

6. Nel A, Xia T, Madler L, Li N. Toxic potential of materials at the nanolevel. Science. 2006;311(5761):622-627.

7. Yallapu MM, Chauhan N, Othman SF, et al. Implications of protein corona on physico-chemical and biological properties of magnetic nanoparticles. Biomaterials. 2015;46:1-12.

8. Johnson BM, Fraietta JA, Gracias DT, et al. Acute exposure to ZnO nanoparticles induces autophagic immune cell death. Nanotoxicology. 2015;9(6):737-748.

9. Borm PJA, Robbins D, Haubold S, et al. The potential risks of nanomaterials: a review carried out for ECETOC. Part Fibre Toxicol. 2006;3:11.

10. Galdiero S, Falanga A, Vitiello M, Cantisani M, Marra V, Galdiero M. Silver nanoparticles as potential antiviral agents. Molecules. 2011; 16(10):8894-8918

11. Oberdörster G, Stone V, Donaldson K. Toxicology of nanoparticles: a historical perspective. Nanotoxicology. 2007;1(1):2-25.

12. Jang GH, Hwang MP, Kim SY, Jang HS, Lee KY. A systematic in-vivo toxicity evaluation of nanophosphor particles via zebrafish models. Biomaterials. 2014;35(1):440-449.

13. Turnlund JR. Copper. In: Shils ME, Olson JA, Shike M, Ross AC, editors. Modern Nutrition in Health and Disease. Baltimore, MD: Lippincott Williams and Wilkins; 1999:241-252.

14. Uauy R, Olivares M, Gonzalez M. Essentiality of copper in humans. Am J Clin Nutr. 1998;67(suppl 5):S952-S959.

15. Björn PZ, Hermann HD, Max L, Heide S, Barabara KG, Hartmut D. Epidemiological investigation on chronic copper toxicity to children exposed via the public drinking water supply. Sci Total Environ. 2003; 302(1-3):127-144.

16. Galhardi CM, Diniz YS, Faine LA, et al. Toxicity of copper intake: lipid profile, oxidative stress and susceptibility to renal dysfunction. Food Chem Toxicol. 2004;42(12):2053-2060.

17. Chen Z, Meng H, Xing GM, et al. Acute toxicological effects of copper nanoparticles in vivo. Toxicol Lett. 2006;163(2):109-120.

18. Donaldson K, Li XY, Mac NW. Ultrafine (nanometer) particle mediated lung injury. J Aerosol Sci. 1998;29(5-6):553-560.

19. Warheit DB, Laurence BR, Reed KL, Roach DH, Reynolds G, Webb TR. Comparative pulmonary toxicity assessment of single-wall carbon nanotubes in rats. Toxicol Sci. 2004;77(1):117-125.

20. Ebrahimnia-Bajestan E, Niazmand H, Duangthongsuk W, Wongwises S. Numerical investigation of effective parameters in convective heat transfer of nanofluids flowing under a laminar flow regime. Int $J$ Heat Mass Transf. 2011;54(19-20):4376-4388.

21. Bondarenko O, Juganson K, Ivask A, Kasemets K, Mortimer M, Kahru A. Toxicity of $\mathrm{Ag}, \mathrm{CuO}$ and $\mathrm{ZnO}$ nanoparticles to selected environmentally relevant test organisms and mammalian cells in vitro: a critical review. Arch Toxicol. 2013;87(7):1181-1200.

22. Das R, Gang S, Nath SS, Bhattacharjee R. Linoleic acid capped copper nanoparticles for antibacterial activity. J Bionanosci. 2010;4(1): $82-86$.

23. Esteban-Tejeda L, Malpartida F, Esteban-Cubillo A, Pecharroman C, Moya JS. Antibacterial and antifungal activity of a soda-lime glass containing copper nanoparticles. Nanotechnology. 2009;20(50):505701.

24. Ingle AP, Duran N, Rai M. Bioactivity, mechanism of action, and cytotoxicity of copper-based nanoparticles: a review. Appl Microbiol Biotechnol. 2014;98(3):1001-1009. 
25. Cho WS, Duffin R, Poland CA, et al. Differential pro-inflammatory effects of metal oxide nanoparticles and their soluble ions in vitro and in vivo; zinc and copper nanoparticles, but not their ions, recruit eosinophils to the lungs. Nanotoxicology. 2012;6(1):22-35.

26. Fahmy B, Cormier SA. Copper oxide nanoparticles induce oxidative stress and cytotoxicity in airway epithelial cells. Toxicol In Vitro. 2009;23(7):1365-1371.

27. Kahru A, Savolainen K. Potential hazard of nanoparticles: from properties to biological and environmental effects. Toxicology. 2010;269(2-3):89-91.

28. Prabhu BM, Ali SF, Murdock RC, Hussain SM, Srivatsan M. Copper nanoparticles exert size and concentration dependent toxicity on somatosensory neurons of rat. Nanotoxicology. 2010;4(2):150-160.

29. Rodhe Y, Skoglund S, Wallinder IO, Potacova Z, Moller L. Copperbased nanoparticles induce high toxicity in leukemic HL60 cells. Toxicol In Vitro. 2015;29(7):1711-1719.

30. Siddiqui MA, Alhadlaq HA, Ahmad J, Al-Khedhairy AA, Musarrat J, Ahamed M. Copper oxide nanoparticles induced mitochondria mediated apoptosis in human hepatocarcinoma cells. PLoS One. 2013;8(8): e69534.

31. Xu J, Li Z, Xu P, Xiao L, Yang Z. Nanosized copper oxide induces apoptosis through oxidative stress in podocytes. Arch Toxicol. 2013; 87(6):1067-1073.

32. Karlsson HL, Gustafsson J, Cronholm P, Moller L. Size-dependent toxicity of metal oxide particles - a comparison between nano- and micrometer size. Toxicol Lett. 2009;188(2):112-118.

33. Lei RH, Wu CQ, Yang BH, et al. Integrated metabolomic analysis of the nano-sized copper particle-induced hepatotoxicity and nephrotoxicity in rats: a rapid in vivo screening method for nanotoxicity. Toxicol Appl Pharmacol. 2008;232(2):292-301.

34. Manna P, Ghosh M, Ghosh J, Das J, Sil PC. Contribution of nanocopper particles to in vivo liver dysfunction and cellular damage: role of $\mathrm{I} \kappa \mathrm{B} \alpha / \mathrm{NF}-\kappa \mathrm{B}, \mathrm{MAPKs}$ and mitochondrial signal. Nanotoxicology. 2012;6(1):1-21.

35. Meng H, Chen Z, Xing GM, et al. Ultrahigh reactivity provokes nanotoxicity: explanation of oral toxicity of nano-copper particles. Toxicol Lett. 2007;175(1-3):102-110.

36. Chun AL. Will the public swallow nanofood? Nat Nanotechnol. 2009;4(12):790-791.

37. Rashidi L, Khosravi-Darani K. The applications of nanotechnology in food industry. Crit Rev Food Sci Nutr. 2011;51(8):723-730.

38. Wurster DE, Burke GM, Berg MJ, Veng-Pedersen P, Schottelius DD Phenobarbital adsorption from simulated intestinal fluid, U.S.P., and simulated gastric fluid, U.S.P., by two activated charcoals. Pharm Res. 1988;5(3):183-186.

39. Organization for Economic Cooperation and Development [webpage on the Internet]. Acute Oral Toxicity-Acute Toxic Class Method. Test Guideline No. 423; 2001. Available from: https://ntp.niehs.nih.gov/ iccvam/suppdocs/feddocs/oecd/oecd_gl423.pdf. Accessed February 5, 2016.
40. Organization for Economic Cooperation and Development [webpage on the Internet]. Acute Oral Toxicity-Fixed Dose Procedure. Test Guideline No. 420; 2001. Available from: https://ntp.niehs.nih.gov/ iccvam/suppdocs/feddocs/oecd/oecd_g1420.pdf. Accessed February 5, 2016.

41. Miller LC, Tainter ML. Estimation of the ED50 and its error by means of logarithmic-probit graph paper. Proc Soc Exp Biol Med. 1944;57(2): 261-264.

42. Lanone S, Boczkowski J. Biomedical applications and potential health risks of nanomaterials: molecular mechanisms. Curr Mol Med. 2006;6(6):651-663.

43. Franklin NM, Rogers NJ, Apte SC, Batley GE, Gadd GE, Casey PS. Comparative toxicity of nanoparticulate $\mathrm{ZnO}$, bulk $\mathrm{ZnO}$, and $\mathrm{ZnCl} 2$ to a freshwater microalga (Pseudokirchneriella subcapitata): the importance of particle solubility. Environ Sci Technol. 2007;41(24):8484-8490.

44. Xia T, Kovochich M, Liong M, et al. Comparison of the mechanism of toxicity of zinc oxide and cerium oxide nanoparticles based on dissolution and oxidative stress properties. ACS Nano. 2008;2(10): 2121-2134.

45. Xie Y, Williams NG, Tolic A, et al. Aerosolized $\mathrm{ZnO}$ nanoparticles induce toxicity in alveolar type II epithelial cells at the air-liquid interface. Toxicol Sci. 2012;125(2):450-461.

46. Bergin IL, Witzmann FA. Nanoparticle toxicity by the gastrointestinal route: evidence and knowledge gaps. Int J Biomed Nanosci Nanotechnol. 2013;3(1-2):163-210.

47. Oberdörster G, Maynard A, Donaldson K, et al; ILSI Research Foundation/Risk Science Institute Nanomaterial Toxicity Screening Working Group. Principles for characterizing the potential human health effects from exposure to nanomaterials: elements of a screening strategy. Part Fibre Toxciol. 2005;2:8.

48. Abbott LC, Maynard AD. Exposure assessment approaches for engineered nanomaterials. Risk Anal. 2010;30(11):1634-1644.

49. Cho WS, Kang BC, Lee JK, Jeong J, Che JH, Seok SH. Comparative absorption, distribution, and excretion of titanium dioxide and zinc oxide nanoparticles after repeated oral administration. Part Fibre Toxicol. 2013;10:9.

50. Loeschner K, Hadrup N, Qvortrup K, et al. Distribution of silver in rats following 28 days of repeated oral exposure to silver nanoparticles or silver acetate. Part Fibre Toxicol. 2011;8:18.

51. Lim CH, Han JH, Cho HW, Kang MG. Studies on the toxicity and distribution of indium compounds according to particle size in SpragueDawley rats. Toxicol Res. 2014;30(1):55-63.

52. Tao TY, Liu FL, Klomp L, Wijmenga C, Gitlin DJ. The copper toxicosis gene product Murrl directly interacts with the Wilson disease protein J Biol Chem. 2004;278(43):41593-41596.

53. Turnlund JR. Human whole-body copper metabolism. Am J Clin Nutr. 1998;67(5):960-964. 


\section{Supplementary materials}

Table SI Absolute and relative organ weights in rats treated with Cu NPs

\begin{tabular}{|c|c|c|c|c|c|}
\hline \multirow[t]{2}{*}{ Items } & \multicolumn{5}{|c|}{ Cu NPs (mg/kg) } \\
\hline & 0 & 312 & 625 & 1,250 & 2,500 \\
\hline \multicolumn{6}{|l|}{ Male } \\
\hline Number of rats & 5 & 5 & 5 & 5 & - \\
\hline Body weight at term & $4|2.6 \pm 6.0|$ & $406.7 \pm \mid 6.31$ & $403.0 \pm 26.41$ & $375.0 \pm 30.99$ & - \\
\hline Brain $(g)$ & $1.90 \pm 0.021$ & $1.87 \pm 0.022$ & $1.88 \pm 0.079$ & $1.82 \pm 0.081$ & - \\
\hline Per bw (\%) & $0.45 \pm 0.003$ & $0.45 \pm 0.018$ & $0.44 \pm 0.030$ & $0.52 \pm 0.080$ & - \\
\hline Liver $(\mathrm{g})$ & $|4.94 \pm 0.73|$ & $14.9 \mid \pm 1.633$ & $15.20 \pm 0.982$ & $1.33 \pm 1.327$ & - \\
\hline Per bw (\%) & $3.61 \pm 0.232$ & $3.58 \pm 0.468$ & $3.65 \pm 0.177$ & $4.07 \pm 0.283^{*}$ & - \\
\hline Spleen (g) & $0.86 \pm 0.042$ & $0.83 \pm 0.040$ & $0.88 \pm 0.033$ & $0.76 \pm 0.056$ & - \\
\hline Per bw (\%) & $0.21 \pm 0.016$ & $0.21 \pm 0.018$ & $0.21 \pm 0.020$ & $0.21 \pm 0.024$ & - \\
\hline Heart (g) & $|.20 \pm 0.07|$ & $1.19 \pm 0.048$ & $1.25 \pm 0.080$ & $1.06 \pm 0.103^{*}$ & - \\
\hline Per bw (\%) & $0.28 \pm 0.023$ & $0.29 \pm 0.018$ & $0.30 \pm 0.017$ & $0.30 \pm 0.021$ & - \\
\hline Thymus (g) & $0.59 \pm 0.071$ & $0.58 \pm 0.026$ & $0.56 \pm 0.083$ & $0.42 \pm 0.173^{*}$ & - \\
\hline Per bw (\%) & $0.13 \pm 0.028$ & $0.13 \pm 0.014$ & $0.13 \pm 0.017$ & $0.12 \pm 0.039$ & - \\
\hline Lung (g) & $1.51 \pm 0.163$ & $1.52 \pm 0.118$ & $1.63 \pm 0.055$ & $1.43 \pm 0.133$ & - \\
\hline Per bw (\%) & $0.35 \pm 0.026$ & $0.37 \pm 0.033$ & $0.38 \pm 0.025$ & $0.4 \mathrm{I} \pm 0.036 *$ & - \\
\hline Kidneys (g) & $2.53 \pm 0.014$ & $2.55 \pm 0.029$ & $2.90 \pm 0.193$ & $3.13 \pm 0.634^{*}$ & - \\
\hline Per bw (\%) & $0.61 \pm 0.005$ & $0.62 \pm 0.010$ & $0.69 \pm 0.029$ & $0.86 \pm 0.165^{* *}$ & - \\
\hline Adrenal glands (g) & $0.048 \pm 0.0007$ & $0.049 \pm 0.0012$ & $0.050 \pm 0.0048$ & $0.047 \pm 0.0100$ & - \\
\hline Per bw (\%) & $0.012 \pm 0.0013$ & $0.012 \pm 0.0016$ & $0.012 \pm 0.0016$ & $0.014 \pm 0.0047$ & - \\
\hline Testes $(\mathrm{g})$ & $3.45 \pm 0.269$ & $3.40 \pm 0.099$ & $3.4 I \pm 0.248$ & $3.28 \pm 0.291$ & - \\
\hline Per bw (\%) & $0.84 \pm 0.031$ & $0.82 \pm 0.023$ & $0.81 \pm 0.062$ & $0.93 \pm 0.07 I^{*}$ & - \\
\hline Prostate (g) & $0.63 \pm 0.048$ & $0.65 \pm 0.034$ & $0.74 \pm 0.135$ & $0.72 \pm 0.282$ & - \\
\hline Per bw (\%) & $0.15 \pm 0.022$ & $0.16 \pm 0.016$ & $0.17 \pm 0.024$ & $0.20 \pm 0.072$ & - \\
\hline Seminal vesicles $(g)$ & $2.06 \pm 0.276$ & $2.01 \pm 0.198$ & $1.68 \pm 0.114$ & I. $44 \pm 0.458 *$ & - \\
\hline Per bw (\%) & $0.50 \pm 0.035$ & $0.48 \pm 0.022$ & $0.40 \pm 0.008 *$ & $0.40 \pm 0.095 *$ & - \\
\hline Epididymides (g) & $1.06 \pm 0.092$ & $1.05 \pm 0.047$ & $1.01 \pm 0.068$ & $0.89 \pm 0.107^{*}$ & - \\
\hline Per bw (\%) & $0.26 \pm 0.011$ & $0.25 \pm 0.010$ & $0.24 \pm 0.020$ & $0.25 \pm 0.019$ & - \\
\hline \multicolumn{6}{|l|}{ Female } \\
\hline Number of rats & 5 & 5 & 5 & 5 & 2 \\
\hline Body weight at term & $257.4 \pm 13.18$ & $255.3 \pm|4.7|$ & $255.7 \pm 13.23$ & $244.2 \pm 11.17$ & $235.6 \pm 11.90$ \\
\hline Brain $(g)$ & $1.69 \pm 0.064$ & $1.78 \pm 0.069$ & $1.83 \pm 0.095$ & $1.76 \pm 0.160$ & $1.77 \pm 0.015$ \\
\hline Per bw (\%) & $0.72 \pm 0.032$ & $0.70 \pm 0.081$ & $0.72 \pm 0.100$ & $0.72 \pm 0.057$ & $0.76 \pm 0.110$ \\
\hline Liver $(g)$ & $8.27 \pm 0.898$ & $8.46 \pm 0.912$ & $8.65 \pm 1.360$ & $8.52 \pm 0.901$ & $8.20 \pm 1.262$ \\
\hline Per bw (\%) & $3.21 \pm 0.389$ & $3.31 \pm 0.214$ & $3.37 \pm 0.198$ & $3.48 \pm 0.150$ & $3.47 \pm 0.086$ \\
\hline Spleen (g) & $0.69 \pm 0.021$ & $0.69 \pm 0.019$ & $0.68 \pm 0.097$ & $0.67 \pm 0.082$ & $0.5 I \pm 0.067$ \\
\hline Per bw (\%) & $0.27 \pm 0.012$ & $0.27 \pm 0.017$ & $0.26 \pm 0.016$ & $0.27 \pm 0.045$ & $0.22 \pm 0.050$ \\
\hline Heart (g) & $0.78 \pm 0.078$ & $0.80 \pm 0.063$ & $0.85 \pm 0.050$ & $0.85 \pm 0.052$ & $0.80 \pm 0.031$ \\
\hline Per bw (\%) & $0.30 \pm 0.034$ & $0.31 \pm 0.027$ & $0.33 \pm 0.024$ & $0.35 \pm 0.0142$ & $0.34 \pm 0.041$ \\
\hline Thymus (g) & $0.35 \pm 0.021$ & $0.35 \pm 0.028$ & $0.38 \pm 0.062$ & $0.35 \pm 0.067$ & $0.24 \pm 0.042 * *$ \\
\hline Per bw (\%) & $0.15 \pm 0.010$ & $0.15 \pm 0.009$ & $0.16 \pm 0.007$ & $0.17 \pm 0.028$ & $0.11 \pm 0.037^{*}$ \\
\hline Lung (g) & $1.30 \pm 0.212$ & $1.31 \pm 0.164$ & $1.33 \pm 0.297$ & $1.22 \pm 0.101$ & $1.20 \pm 0.067$ \\
\hline Per bw (\%) & $0.5 I \pm 0.089$ & $0.5 I \pm 0.047$ & $0.5 I \pm 0.065$ & $0.50 \pm 0.034$ & $0.52 \pm 0.085$ \\
\hline Kidneys (g) & $1.61 \pm 0.07 \mid$ & $1.68 \pm 0.131$ & $1.60 \pm 0.126$ & $1.64 \pm 0.152$ & $1.68 \pm 0.158$ \\
\hline Per bw (\%) & $0.63 \pm 0.035$ & $0.67 \pm 0.021$ & $0.63 \pm 0.017$ & $0.67 \pm 0.05 \mid$ & $0.72 \pm 0.079 *$ \\
\hline Adrenal glands (g) & $0.064 \pm 0.0190$ & $0.064 \pm 0.007 \mid$ & $0.06 I \pm 0.004 I$ & $0.064 \pm 0.0049$ & $0.07 I \pm 0.0075$ \\
\hline Per bw (\%) & $0.025 \pm 0.007 \mid$ & $0.024 \pm 0.0022$ & $0.024 \pm 0.0027$ & $0.026 \pm 0.001 \mathrm{I}$ & $0.031 \pm 0.0070$ \\
\hline Ovaries $(\mathrm{g})$ & $0.099 \pm 0.0253$ & $0.097 \pm 0.0103$ & $0.078 \pm 0.0077$ & $0.102 \pm 0.0112$ & $0.086 \pm 0.0191$ \\
\hline Per bw (\%) & $0.038 \pm 0.0094$ & $0.037 \pm 0.0043$ & $0.031 \pm 0.0055$ & $0.042 \pm 0.0065$ & $0.036 \pm 0.0039$ \\
\hline
\end{tabular}

Notes: Values are presented as mean \pm SD. “_” indicates no record of organ weights. $* P<0.05, * * P<0.0$ I vs vehicle control.

Abbreviations: Cu NPs, copper nanoparticles; bw, body weight; SD, standard deviation. 
Table S2 Absolute and relative organ weights in rats treated with $\mathrm{Cu}$ ions

\begin{tabular}{|c|c|c|c|c|c|}
\hline \multirow[t]{2}{*}{ Items } & \multicolumn{5}{|c|}{$\mathrm{Cu}$ ions $(\mathrm{mg} / \mathrm{kg})$} \\
\hline & 0 & 156 & 312 & 625 & 1,250 \\
\hline \multicolumn{6}{|l|}{ Male } \\
\hline Number of rats & 5 & 5 & 5 & 3 & - \\
\hline Body weight at term & $4 \mid 2.6 \pm 6.01$ & $404.9 \pm 13.11$ & $382.3 \pm 8.26$ & $382.3 \pm 30.63$ & - \\
\hline Brain $(g)$ & $1.90 \pm 0.021$ & $1.98 \pm 0.08 \mid$ & $1.94 \pm 0.075$ & $2.00 \pm 0.275$ & - \\
\hline Per bw (\%) & $0.45 \pm 0.003$ & $0.49 \pm 0.026$ & $0.52 \pm 0.072$ & $0.50 \pm 0.053$ & - \\
\hline Liver $(\mathrm{g})$ & $|4.94 \pm 0.73|$ & $14.36 \pm 1.015$ & $13.44 \pm 0.668$ & $14.92 \pm 3.057$ & - \\
\hline Per bw (\%) & $3.61 \pm 0.232$ & $3.54 \pm 0.212$ & $3.61 \pm 0.102$ & $3.69 \pm 0.332$ & - \\
\hline Spleen $(g)$ & $0.86 \pm 0.042$ & $0.82 \pm 0.037$ & $0.80 \pm 0.07 \mid$ & $0.89 \pm 0.110$ & - \\
\hline Per bw (\%) & $0.21 \pm 0.016$ & $0.20 \pm 0.024$ & $0.21 \pm 0.017$ & $0.22 \pm 0.022$ & - \\
\hline Heart (g) & $1.20 \pm 0.07 \mid$ & $1.15 \pm 0.062$ & $1.10 \pm 0.060$ & I. $14 \pm 0.185$ & - \\
\hline Per bw (\%) & $0.28 \pm 0.023$ & $0.28 \pm 0.023$ & $0.29 \pm 0.010$ & $0.28 \pm 0.018$ & - \\
\hline Thymus (g) & $0.59 \pm 0.071$ & $0.52 \pm 0.05 \mathrm{I}$ & $0.49 \pm 0.124$ & $0.46 \pm 0.102$ & - \\
\hline Per bw (\%) & $0.13 \pm 0.028$ & $0.13 \pm 0.038$ & $0.13 \pm 0.0305$ & $0.12 \pm 0.0367$ & - \\
\hline Lung (g) & $1.51 \pm 0.163$ & $1.48 \pm 0.083$ & $1.46 \pm 0.044$ & $1.59 \pm 0.127$ & - \\
\hline Per bw (\%) & $0.35 \pm 0.026$ & $0.37 \pm 0.026$ & $0.39 \pm 0.014$ & $0.40 \pm 0.064$ & - \\
\hline Kidneys (g) & $2.53 \pm 0.014$ & $2.47 \pm 0.028$ & $2.44 \pm 0.186$ & $2.70 \pm 0.419$ & - \\
\hline Per bw (\%) & $0.6 \mathrm{I} \pm 0.005$ & $0.61 \pm 0.019$ & $0.65 \pm 0.036$ & $0.67 \pm 0.027 * *$ & - \\
\hline Adrenal glands (g) & $0.048 \pm 0.0007$ & $0.048 \pm 0.003$ & $0.048 \pm 0.006$ & $0.048 \pm 0.003$ & - \\
\hline Per bw (\%) & $0.012 \pm 0.0013$ & $0.012 \pm 0.001$ & $0.013 \pm 0.002$ & $0.012 \pm 0.002$ & - \\
\hline Testes (g) & $3.45 \pm 0.269$ & $3.51 \pm 0.219$ & $3.5 \mathrm{I} \pm 0.249$ & $3.53 \pm 0.326$ & - \\
\hline Per bw (\%) & $0.84 \pm 0.031$ & $0.87 \pm 0.057$ & $0.94 \pm 0.049$ & $0.88 \pm 0.118$ & - \\
\hline Prostate (g) & $0.63 \pm 0.048$ & $0.65 \pm 0.071$ & $0.68 \pm 0.105$ & $0.67 \pm 0.192$ & - \\
\hline Per bw (\%) & $0.15 \pm 0.022$ & $0.16 \pm 0.022$ & $0.15 \pm 0.053$ & $0.17 \pm 0.050$ & - \\
\hline Seminal vesicles $(g)$ & $2.06 \pm 0.276$ & $1.88 \pm 0.276$ & $1.68 \pm 0.376$ & $1.67 \pm 0.186$ & - \\
\hline Per bw (\%) & $0.50 \pm 0.035$ & $0.464 \pm 0.102$ & $0.452 \pm 0.103$ & $0.408 \pm 0.044$ & - \\
\hline Epididymides (g) & $1.06 \pm 0.092$ & $1.07 \pm 0.048$ & $1.08 \pm 0.015$ & $1.01 \pm 0.132$ & - \\
\hline Per bw (\%) & $0.26 \pm 0.011$ & $0.26 \pm 0.013$ & $0.26 \pm 0.010$ & $0.25 \pm 0.028$ & - \\
\hline \multicolumn{6}{|l|}{ Female } \\
\hline Number of rats & 5 & 5 & 4 & 3 & - \\
\hline Body weight at term & $257.4 \pm 13.18$ & $261.7 \pm 10.37$ & $254.0 \pm 17.64$ & $241.8 \pm 2.40$ & - \\
\hline Brain $(g)$ & $1.69 \pm 0.064$ & $1.78 \pm 0.078$ & $1.80 \pm 0.132$ & $1.75 \pm 0.127$ & - \\
\hline Per bw (\%) & $0.72 \pm 0.032$ & $0.68 \pm 0.024$ & $0.7 I \pm 0.004$ & $0.72 \pm 0.060$ & - \\
\hline Liver (g) & $8.27 \pm 0.898$ & $8.47 \pm 0.716$ & $8.59 \pm 1.212$ & $8.34 \pm 0.021$ & - \\
\hline Per bw (\%) & $3.21 \pm 0.389$ & $3.24 \pm 0.297$ & $3.37 \pm 0.258$ & $3.45 \pm 0.026$ & - \\
\hline Spleen $(g)$ & $0.69 \pm 0.021$ & $0.67 \pm 0.035$ & $0.63 \pm 0.058$ & $0.53 \pm 0.07 \mid * *$ & - \\
\hline Per bw (\%) & $0.27 \pm 0.012$ & $0.26 \pm 0.019$ & $0.25 \pm 0.008$ & $0.22 \pm 0.027 * *$ & - \\
\hline Heart $(g)$ & $0.78 \pm 0.078$ & $0.8 I \pm 0.056$ & $0.84 \pm 0.062$ & $0.82 \pm 0.042$ & - \\
\hline Per bw (\%) & $0.30 \pm 0.034$ & $0.3 I \pm 0.027$ & $0.33 \pm 0.012$ & $0.34 \pm 0.021$ & - \\
\hline Thymus (g) & $0.35 \pm 0.021$ & $0.37 \pm 0.098$ & $0.43 \pm 0.121$ & $0.38 \pm 0.035$ & - \\
\hline Per bw (\%) & $0.15 \pm 0.010$ & $0.14 \pm 0.033$ & $0.17 \pm 0.045$ & $0.20 \pm 0.017^{*}$ & - \\
\hline Lung (g) & $1.30 \pm 0.212$ & $1.31 \pm 0.122$ & $1.19 \pm 0.098$ & $1.12 \pm 0.127$ & - \\
\hline Per bw (\%) & $0.51 \pm 0.089$ & $0.50 \pm 0.031$ & $0.47 \pm 0.012$ & $0.46 \pm 0.048$ & - \\
\hline Kidneys (g) & $1.61 \pm 0.07 \mid$ & $1.68 \pm 0.074$ & $1.53 \pm 0.060$ & $1.80 \pm 0.163$ & - \\
\hline Per bw (\%) & $0.63 \pm 0.035$ & $0.64 \pm 0.046$ & $0.60 \pm 0.044$ & $0.74 \pm 0.075^{*}$ & - \\
\hline Adrenal glands (g) & $0.064 \pm 0.0190$ & $0.067 \pm 0.0092$ & $0.07 I \pm 0.0054$ & $0.060 \pm 0.0087$ & - \\
\hline Per bw (\%) & $0.025 \pm 0.007 \mid$ & $0.026 \pm 0.0057$ & $0.028 \pm 0.004 \mid$ & $0.025 \pm 0.0034$ & - \\
\hline Ovaries (g) & $0.099 \pm 0.0253$ & $0.091 \pm 0.0178$ & $0.085 \pm 0.0220$ & $0.101 \pm 0.0148$ & - \\
\hline Per bw (\%) & $0.038 \pm 0.0094$ & $0.035 \pm 0.008 I$ & $0.033 \pm 0.0077$ & $0.042 \pm 0.0064$ & - \\
\hline
\end{tabular}

Notes: Values are presented as mean $\pm S D$. “-” indicates no record of organ weights. $* P<0.05, * * P<0.01$ vs vehicle control. Abbreviations: bw, body weight; SD, standard deviation. 


\section{Publish your work in this journal}

The International Journal of Nanomedicine is an international, peerreviewed journal focusing on the application of nanotechnology in diagnostics, therapeutics, and drug delivery systems throughout the biomedical field. This journal is indexed on PubMed Central,

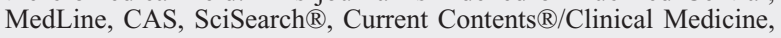

Journal Citation Reports/Science Edition, EMBase, Scopus and the Elsevier Bibliographic databases. The manuscript management system is completely online and includes a very quick and fair peer-review system, which is all easy to use. Visit http://www.dovepress.com/ testimonials.php to read real quotes from published authors.

Submit your manuscript here: http://www.dovepress.com/international-journal-of-nanomedicine-journal 